SANDIA REPORT

SAND96-2090 • UC-903

Unlimited Release

Printed August 1996
Mn: 301056

UST

\title{
Unsaturated Hydrologic Flow Parameters Based on Laboratory and Field Data For Soils Near the Mixed Waste Landfill, Technical Area III, Sandia National Laboratories/New Mexico
}

Craig S. Roepke, Warren R. Strong, Huy A. Nguyen, Michael D. Mu Vey, Timothy J. Goering

Prepared by

Sandia National Laboratories

Albuquerque, New Mexico 87185 and Livermore, California 94550

for the United States Department: of Energy

under Contract DE-AC04-94AL85000

Approved for public release; distribution is ex

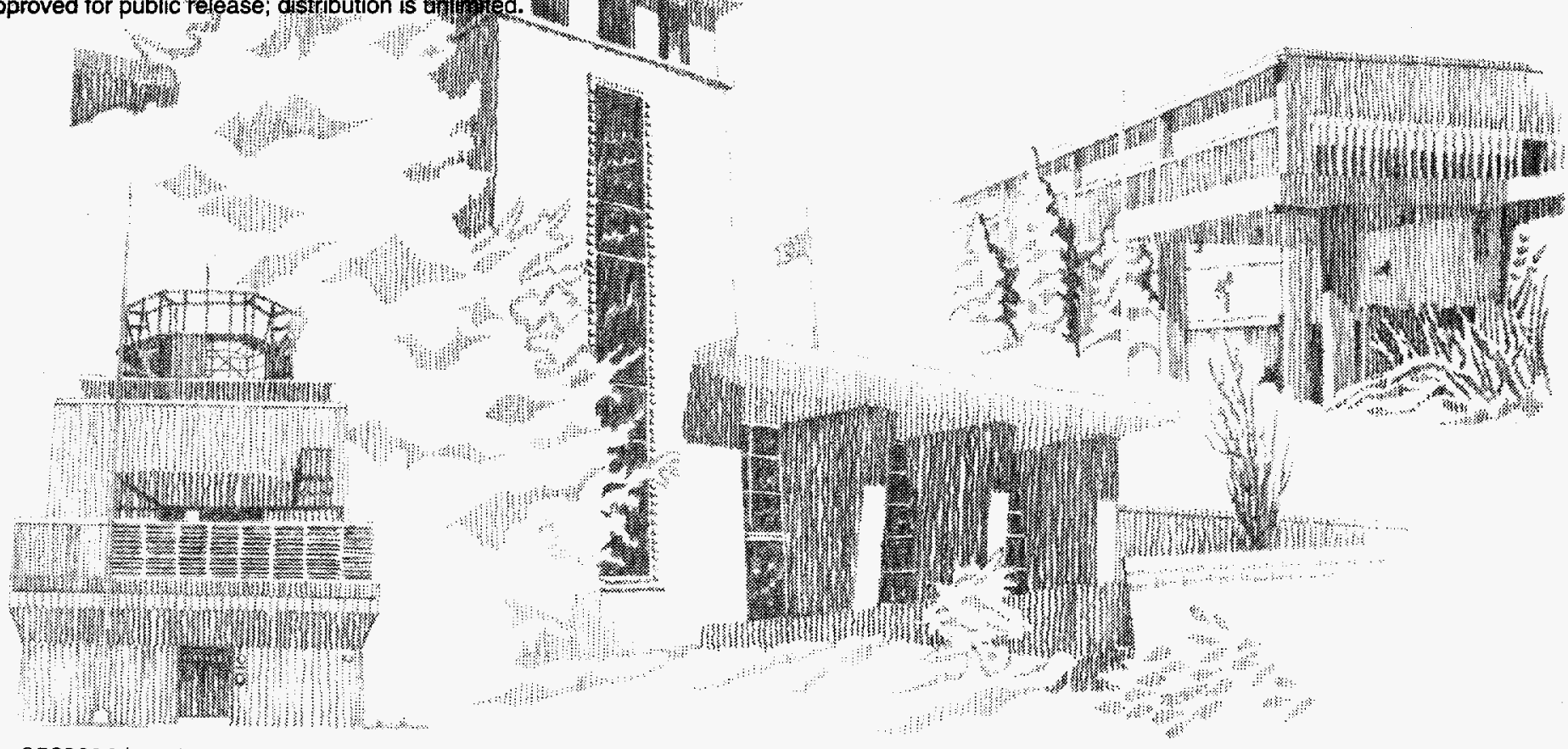

$S F 29000(8-81)$ 
Issued by Sandia National Laboratories, operated for the United States Department of Energy by Sandia Corporation.

NOTICE: This report was prepared as an account of work sponsored by an agency of the United States Government. Neither the United States Government nor any agency thereof, nor any of their employees, nor any of their contractors, subcontractors, or their employees, makes any warranty, express or implied, or assumes any legal liability or responsibility for the accuracy, completeness, or usefulness of any information, apparatus, product, or process disclosed, or represents that its use would not infringe privately owned rights. Reference herein to any specific commercial product, process, or service by trade name, trademark, manufacturer, or otherwise, does not necessarily constitute or imply its endorsement, recommendation, or favoring by the United States Government, any agency thereof or any of their contractors or subcontractors. The views and opinions expressed herein do not necessarily state or reflect those of the United States Government, any agency thereof or any of their contractors.

Printed in the United States of America. This report has been reproduced directly from the best available copy.

Available to DOE and DOE contractors from

Office of Scientific and Technical Information

PO Box 62

Oak Ridge, TN 37831

Prices available from (615) 576-8401, FTS 626-8401

Available to the public from

National Technical Information Service

US Department of Commerce

5285 Port Royal Rd

Springfield, VA 22161

NTIS price codes

Printed copy: A03

Microfiche copy: A01 


\title{
Unsaturated Hydrologic Flow Parameters Based on Laboratory and Field Data For Soils Near the Mixed Waste Landfill, Technical Area III, Sandia National Laboratories/New Mexico
}

\author{
Craig S. Roepke \\ INTERA, Inc. \\ 1650 University Boulevard, \\ Albuquerque, NM 87102 \\ Warren R. Strong and Huy A. Nguyen \\ Environmental Restoration Project \\ Sandia National Laboratories \\ Albuquerque, NM 87185 \\ Michael D. McVey and Timothy J. Goering \\ GRAM, Inc. \\ 8500 Menaul Blvd., NE, Suite B-370 \\ Albuquerque, NM 87112
}

\begin{abstract}
This report presents the results of laboratory tests conducted on soil core samples obtained prior to an instantaneous profile test conducted west of the Mixed Waste Landfill in Technical Area III. The instantaneous profile test was conducted to measure in situ hydrologic parameters controlling unsaturated flow and contaminant transport in the nearsurface vadose zone. Soil core samples from the instantaneous profile test plot were tested in the Sandia National Laboratory's Environmental Restoration Project Hydrology Laboratory to measure saturated hydraulic conductivity and the relationships between moisture content and soil water tension. Data from laboratory tests and the instantaneous profile field test were then modeled using the computer code RETC to quantify moisture content, soil water tension, and unsaturated hydraulic conductivity relationships. Results verified that a combination of laboratory and field data yielded a more complete definition of hydrologic properties than either laboratory or field data alone. Results also indicated that at native moisture contents, the potential for significant unsaturated aqueous flow is limited, while at saturated or near-saturated conditions, preferential flow may occur.
\end{abstract}




\section{Acknowledgments}

The authors wish to thank Jerry Peace (Dept. 7585) for his sponsorship of this project. The authors also wish to acknowledge Randy Roberts (CDM-Federal Programs Center) and Monica Archuleta (CDM-Federal Programs Center) for conducting the laboratory operations so critical to the success of this study. 


\section{DISCLAIMER}

Portions of this document may be illegible in electronic image products. Images are produced from the best available original document. 



\section{Contents}

1.0 Introduction

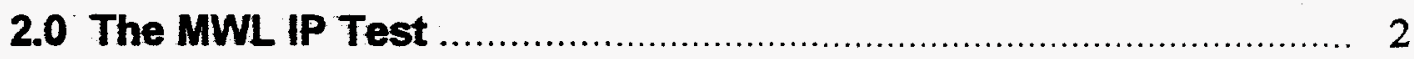

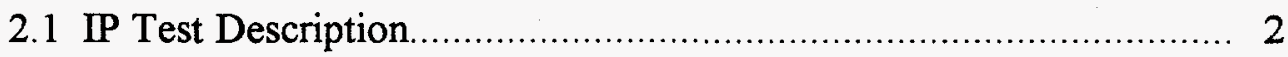

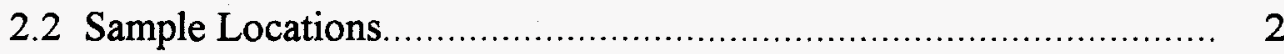

2.3 Sample Preparation and testing ................................................. 2

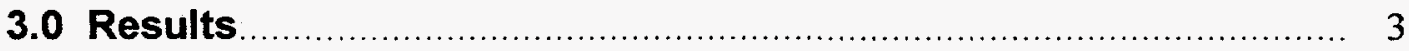

3.1 Fitting of van Genuchten Parameters

and Modeling of $\mathrm{K}(\theta)$ Relationships ..................................... 3

3.2 Saturated Hydraulic Conductivity

Predicted by RETC Modeling ................................................. 4

3.3 Unsaturated Hydraulic Conductivity .............................................. 5

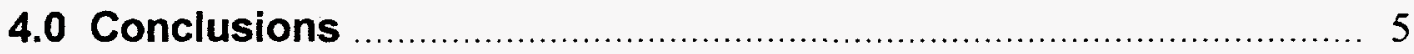

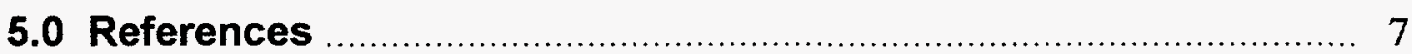

APPENDIX A: RETC Predictions of $\psi(\theta)$ and $K(\theta)$ Relationships for

Soils in the Vadose Zone Near the Mixed Waste Landfill .. A-1 


\section{Tables}

1 RETC-derived parameters from

$\psi(\theta)$ data of laboratory-tested samples.

2 RETC-derived parameters from in situ

$\mathrm{K}(\theta)$ data derived during the IP test.

3 RETC-derived parameters from combined

laboratory $\psi(\theta)$ and in situ $\mathrm{K}(\theta)$ data. 9

\section{Figures}

1 Instantaneous profile test plot location 10

2 Instrument locations in the IP test plot. 11

3 Saturated hydraulic conductivity with depth

4 RETC-predicted hydraulic conductivity-moisture content relationships based on field, laboratory, and combined field and laboratory data

5 RETC predictions of saturated moisture content based on laboratory testing 14

6 Hydraulic conductivity with depth at a volumetric moisture content of 10 percent. 


\section{Nomenclature}

$\begin{array}{ll}\text { bgs } & \text { below ground surface } \\ \text { cm } & \text { centimeter } \\ \text { ER } & \text { Environmental Restoration } \\ \text { IP } & \text { instantaneous profile } \\ \mathrm{K}_{\mathrm{s}} & \text { saturated hydraulic conductivity }[\mathrm{L} / \mathrm{T}] \\ \mathrm{K}_{\mathrm{eff}} & \text { effective hydraulic conductivity }[\mathrm{L} / \mathrm{T}] \\ \mathrm{K}(\theta) & \text { unsaturated hydraulic conductivity as a function of volumetric moisture } \\ \mathrm{m} & \text { content }[\mathrm{L} / \mathrm{T}] \\ \mathrm{MWL} & \text { meter } \\ \mathrm{RETC} & \text { Mixed Waste Landfill } \\ & \text { computer code (van Genuchten et al., } 1994) \text { used to determine the van } \\ \text { SNL/NM } & \text { Genuchten parameters }\left(\theta_{\mathrm{r}}, \theta_{\mathrm{s}}, \alpha, \mathrm{n}, \mathrm{m}, 1, \mathrm{~K}_{\mathrm{s}}\right) \text { describing the hydraulic } \\ \text { SWHC } & \text { properties of soils } \\ \theta_{\mathrm{v}} & \text { Sandia National Laboratories } / \mathrm{New} \mathrm{Mexico} \\ \text { WCR } & \text { Site-Wide Hydrogeologic Characterization } \\ \theta_{\mathrm{r}} & \text { volumetric moisture content }\left[\mathrm{L}^{3} / \mathrm{L}^{3}\right] \\ \text { WCS } & \text { residual volumetric moisture content }\left[\mathrm{L}^{3} / \mathrm{L}^{3}\right] \\ \theta_{\mathrm{s}} & \text { residual volumetric moisture content }\left[\mathrm{L}^{3} / \mathrm{L}^{3}\right] \\ \psi & \text { saturated volumetric moisture content }\left[\mathrm{L}^{3} / \mathrm{L}^{3}\right] \\ \psi(\theta) & \text { saturated volumetric moisture content }\left[\mathrm{L}^{3} / \mathrm{L}^{3}\right] \\ & \text { soil moisture tension }[\mathrm{L}] \\ & \text { soil moisture tension as a function of volumetric moisture content }[\mathrm{L}]\end{array}$





\subsection{Introduction}

Accurate modeling and successful remediation of contaminated sites require that unsaturated flow and contaminant transport be well understood and that relevant hydrologic parameters be accurately quantified. This is particularly true in the semi-arid climate at Sandia National Laboratories/New Mexico (SNL/NM), where the vadose zone can be 150 meters $(\mathrm{m})$ or more in thickness (Crowson et al., 1993).

The SNL Mixed Waste Landfill (MWL) is underlain by a vadose zone extending approximately $140 \mathrm{~m}$ to the water table. This extensive vadose zone dictates that potential subsurface contaminant transport would initially occur as unsaturated flow. Measurement of unsaturated flow parameters and an understanding of their relationships are essential for characterizing contaminant migration.

An instantaneous profile (IP) test was conducted from December 1993 through 1995 as part of the Phase 2 RCRA Facility Investigation (RFI) of the MWL (SNL, 1993). The purpose of the IP test was to measure the hydrologic parameters controlling unsaturated flow and contaminant transport in the near-surface vadose zone at the MWL. Due to the potential for mobilizing contaminants in the MWL soils, the IP test was not conducted at the MWL itself, but $150 \mathrm{~m}$ to the west in uncontaminated soils analogous to those encountered at the MWL. Data from the IP test are presented in Bayliss et al., 1996, and analysis of IP test results are presented in Goering et al., 1995.

While an IP test generally yields accurate in situ measurements of some unsaturated hydrologic flow parameters (Marion et al., 1994), the range of values experienced during a field test is limited due to the considerable time required for residual moisture contents to be reached. Laboratory measurements of soil moisture tension and volumetric moisture content may be made over the full range of possible values and used to augment field-derived results. Field and laboratory results may also be compared to identify soil heterogeneity, structure, or incorrect assumptions inherent in the analysis of field data.

This report presents the results of laboratory tests conducted on core samples obtained from the test plot prior to the actual IP test. The computer code RETC (van Genuchten et al., 1994) was used to fit van Genuchten unsaturated flow parameters to the volumetric moisture content and soil moisture tension relationship $(\Psi(\theta))$ data measured during laboratory testing. The parameters were then used to model the hydraulic conductivity and volumetric moisture content relationship $(\mathrm{K}(\theta))$ over the full range of possible soil moisture contents.

Laboratory testing measured water retention relationships $(\Psi(\theta))$ over extended ranges not experienced during the field test. Field data reflected in situ conditions difficult if not impossible to recreate in a laboratory setting. RETC predictions of $\mathrm{K}(\theta)$ relationships based on in situ field dati were compared with RETC predictions of $K(\theta)$ relationships based on laboratory data to determine the effects of field-scale soil structure on flow. Finally, RETC predictions based on 
combined laboratory and field data sets were made to provide a more complete and accurate data set for modeling unsaturated flow and contaminant transport at the MWL.

\subsection{The MWL IP Test and Sampling}

This section briefly describes the IP test conducted near the MWL, sampling locations, laboratory test methods, and the computer modeling approach using RETC.

\subsection{IP Test description}

The MWL IP test was conducted in an uncontaminated area approximately $150 \mathrm{~m}$ west of the MWL in Technical Area III (Figure 1). Infiltration was constrained to one-dimensional flow using perimeter trenches filled with a $12 \%$ bentonite/soil mixture. The trenches were $0.3 \mathrm{~m}$ wide and $2.0 \mathrm{~m}$ deep. A 30 centimeter $(\mathrm{cm})$ high concrete berm was built around the perimeter of the test plot to allow water to be ponded during the test. Prior to infiltration, the test plot was instrumented with Time Domain Reflectometry (TDR) probes, neutron and frequency domain probe access tubes, buried frequency domain probes, and tensiometers. Figure 2 shows the instrument locations in the IP test plot. Three neutron access tubes were installed to a depth of $3.0 \mathrm{~m}$ inside the test plot. Two additional neutron access tubes were installed outside the test plot to monitor potential leakage from the test plot, and to observe meteoric influences on the soil moisture profile (Goering et al., 1995).

The IP test consisted of flooding a $4.7 \mathrm{~m}$ by $4.7 \mathrm{~m}$ soil plot with 20,300 liters of water for 47.3 hours until the upper two meters of soil were saturated. Movement of the wetting front and subsequent drainage from the IP test plot were monitored with the instruments installed in the plot and a CPN Model 503DR neutron moisture meter. Volumetric moisture contents in the vertical profile continue to be monitored on a monthly basis with the neutron moisture meter.

\subsection{Sample Locations}

The soil core samples used in the laboratory tests were taken during installation of Borehole D in the southwest corner of the IP test plot, adjacent to instrument cluster A (Figure 2). Core samples were collected from 0 to $269 \mathrm{~cm}$ below ground surface (bgs). A two-inch split-spoon sampler was manually driven into the ground to collect the core samples. Due to the dry, friable nature of the soils, completely undisturbed and intact soil core samples were not always obtained.

\subsection{Sample Preparation and testing}

Individual samples were taken from 3 to $15 \mathrm{~cm}$ depth intervals. Where necessary, samples were packed to estimated in situ bulk density in two-inch brass or stainless steel rings. Seventeen samples were tested in the SNL Environmental Restoration Project Hydrology Testing Laboratory for saturated hydraulic conductivity $\left(\mathrm{K}_{\mathrm{s}}\right)$ and the relationships between soil moisture tensions and volumetric moisture content $(\Psi(\theta))$. 
$\Psi(\theta)$ relationships for the core samples were measured using a pressure pot/ceramic plate apparatus as specified in Methods Of Soil Analysis (MOSA), No. 9, Part 1, pp. 637-638 (Klute (ed) 1986). Soil moisture tensions in the pressure pot were varied from 6 to $15,300 \mathrm{~cm} \mathrm{H}_{2} \mathrm{O}$. The saturated hydraulic conductivity of the core samples was measured using the constant-head method described in MOSA, No. 9, Part 1, pp. 694-700.

\subsection{Results}

The IP field infiltration test and the laboratory tests of soil core samples were conducted to study the hydraulic properties of the near-surface vadose zone beneath the MWL. The parametric fitting program RETC (van Genuchten et al., 1994) was used to quantify hydraulic properties.

\subsection{Fitting of van Genuchten Parameters and Modeling of $\mathbf{K}(\theta)$ Relationships}

$\Psi(\theta)$ data from laboratory tests of IP samples and $\mathrm{K}(\theta)$ data derived from the Hillel one-step analysis of the IP test data (Hillel, et al., 1972 and Goering et al., 1995) were used as inputs to the parameter-fitting program RETC (van Genuchten et al., 1994). RETC fits seven parameters $\left(\theta_{s}\right.$, $\theta_{\mathrm{r}}, \alpha, \mathrm{n}, \mathrm{m}, \mathrm{l}$, and $\mathrm{K}_{\mathrm{s}}$ ) to supplied data. After fitting, the program uses the parameters to predict the full range of $\Psi(\theta)$ and $K(\theta)$ relationships.

Parameters were fitted using an iterative approach. Initial parameter estimates were input from expected parameter values for the soil samples (Carsel and Parrish, 1988, and Rawls, et al., 1982). The RETC program was then allowed to fit all parameters to known values (laboratory or field data sets). R-squared and the sum of squares of observed-minus-fitted values were checked to determine fit accuracy. The correlation matrix was also inspected to detect non-unique relationships between parameters. Non-unique relationships not prevented by restrictions on solution methods (e.g., forcing $m=1-1 / n$ ) were then eliminated by arbitrarily fixing one of the parameters involved at a reasonable or tested value (van Genuchten et al., 1994). Once parameters were well-fitted and non-unique relationships eliminated, the entire process was repeated with different original input parameters to insure that the values obtained were global solutions and did not represent local minimums. The parametric model of van Genuchten was then used by RETC to predict the full $\Psi(\theta)$ relationship. The theoretical pore-size distribution model of Mualem was used to predict the full $K(\theta)$ relationship for the sample (van Genuchten et al., 1994).

Neither $\Psi(\theta)$ nor $K(\theta)$ data alone will fit all seven van Genuchten parameters; e.g., $\Psi(\theta)$ data from laboratory testing will not fit $\mathrm{K}_{\mathrm{s}}$, and $\mathrm{K}(\theta)$ data from the IP test will not fit $\alpha$. If simultaneous $\mathrm{K}(\theta)$ and $\Psi(\theta)$ data are not available, some parameter values will have to be measured, assumed, or taken from the literature. However, combining laboratory $\Psi(\theta)$ and field $\mathrm{K}(\theta)$ data provides a complete fitting of all seven parameters (van Genuchten et al., 1994). Parameters fitted using only laboratory $\Psi(\theta)$ data are presented in Table 1. Parameters fitted using only in situ $\mathrm{K}(\theta)$ data are given in Table 2 . Fitted parameters using both data sets are presented in Table 3. 
Graphs showing RETC predictions of $K(\theta)$ and $\psi(\theta)$ hydraulic functions that are based only on laboratory-tested samples are presented in Section 1, Appendix A. Graphs showing RETC predictions of extended $K(\theta)$ relationships from IP in situ $K(\theta)$ data are presented in Section 2, Appendix A. Graphs showing RETC-predicted $\mathrm{K}(\theta)$ relationships from combined laboratory and field data are presented in Section 3, Appendix A. For comparative purposes, the $K(\theta)$ relationships predicted from field and laboratory data alone are also shown on the graphs of $K(\theta)$ relationships from combined data.

\subsection{Saturated Hydraulic Conductivity $\left(\mathrm{K}_{\mathrm{s}}\right)$ Predicted by RETC Modeling}

Figure 3 presents graphs of $\mathrm{K}_{\mathrm{s}}$ with depth from laboratory testing, in situ IP field data, and combined laboratory and IP data. Literature values of $\mathrm{K}_{\mathrm{s}}$ for soils similar to those at the IP test site (loam, sandy loam, silts, and clayey silts) range from $10^{-7}$ centimeters per second $(\mathrm{cm} / \mathrm{s})$ to $10^{-}$ ${ }^{3} \mathrm{~cm} / \mathrm{s}$ (Freeze and Cherry, 1979). Because both laboratory testing and IP flow was essentially perpendicular to the layered heterogeneity of the alluvial deposits studied, effective saturated hydraulic conductivity $\left(\mathrm{K}_{\mathrm{eff}}\right)$ was calculated as:

$$
\mathrm{K}_{\text {off }}=\frac{\sum \mathrm{z}_{\mathrm{i}}}{\Sigma\left(\mathrm{z}_{\mathrm{i}} / \mathrm{K}_{\mathrm{i}}\right)}, \text { where } \begin{aligned}
\mathrm{K}_{\text {erf }} & =\text { effective hydraulic conductivity } \\
\mathrm{z}_{\mathrm{i}} & =\text { depth of the interval } \\
\mathrm{K}_{\mathrm{i}} & =\text { hydraulic conductivity of the interval }
\end{aligned}
$$

Laboratory measurements of $\mathrm{K}_{\mathrm{s}}$ from core samples obtained from the IP test site ranged from 2.0 $\times 10^{-7} \mathrm{~cm} / \mathrm{s}$ to $3.0 \times 10^{-4} \mathrm{~cm} / \mathrm{s}$ (Table 1). The calculated $K_{\text {eff }}$ from laboratory-measured samples was $2.9 \times 10^{-6} \mathrm{~cm} / \mathrm{s}$. $\mathrm{K}_{\mathrm{s}}$ predicted by $\mathrm{RETC}$ based on in situ $\mathrm{K}(\theta)$ data ranged from $2.0 \times 10^{-5}$ $\mathrm{cm} / \mathrm{s}$ to $2.3 \times 10^{-3} \mathrm{~cm} / \mathrm{s}$ (Table 2). The calculated $\mathrm{K}_{\text {eff }}$ from IP field data was $8.6 \times 10^{-5} \mathrm{~cm} / \mathrm{s}$. RETC-predicted values of $\mathrm{K}_{\mathrm{s}}$ based on the data set combining laboratory and field measurements ranged from $2.4 \times 10^{-3} \mathrm{~cm} / \mathrm{s}$ to $9.9 \times 10^{-3} \mathrm{~cm} / \mathrm{s}$ (Table 3). The calculated $\mathrm{K}_{\text {eff }}$ based on combined laboratory and IP field measurements was $4.6 \times 10^{-3} \mathrm{~cm} / \mathrm{s}$.

Laboratory measurement of $\mathrm{K}_{\mathrm{s}}$ may reflect significant sources of error such as loss of in situ structure and heterogeneity, incorrect boundary conditions, or inaccurate bulk density (if repacked from disturbed media). In this study, laboratory measurements of $K_{s}$ were generally lower than $\mathrm{K}_{\mathrm{s}}$ predictions from data gathered during the IP test (Figure 3). Because of the noncohesive nature of soils at the IP test site, samples could not always be collected in a perfectly intact, undisturbed condition. In addition, the small, two-inch diameter of the core samples reduced the ability of the samples to reflect in situ flow features such as macropores and heterogeneity.

The effect of soil structure on $\mathrm{K}_{\mathrm{s}}$ can be illustrated by comparing the RETC-predicted $\mathrm{K}_{\mathrm{s}}$ values from laboratory tests with field-derived values from the IP test (Figure 4). The greatest divergence between laboratory and field predictions of $\mathrm{K}_{\mathrm{s}}$ occurs near the saturated end of the curve, where structure and macropore flow is most possible. As the soil moisture content 
decreases, macropore and fracture flow is less likely, and the difference between laboratory and field results is much less apparent.

Predicted $\mathrm{K}_{\mathrm{s}}$ values from IP test data are lower than $\mathrm{K}_{\mathrm{s}}$ values from combined laboratory and IP data due to the constraints of the IP test. In a short-term ponded infiltration event such as the IP test, the vertical profile rarely reaches complete saturation because of entrapped air in the soil pores. The entrapped air decreases both the measured saturation (Figure 5) and the hydraulic conductivity (Figure 3). In the laboratory environment, deaerated water, vacuum saturation techniques, and the lack of time constraints can eliminate or greatly reduce the quantity of entrapped pore air. As a result, RETC-predictions from IP field data of the $K(\theta)$ relationship at the saturated or near-saturated range yield lower hydraulic conductivity. When laboratory and field data are combined, the higher saturated moisture contents of laboratory testing are reflected in higher predictions of $K_{s}$ (see Figures 3 and 5).

\subsection{Unsaturated Hydraulic Conductivity}

Differences between laboratory, field, and combined laboratory and field predictions of hydraulic conductivity are less significant with decreasing volumetric moisture content (Figure 4). This is probably due to the reduction in preferential flow as fractures and macropores become unsaturated at lower soil moistures.

Based on more than 160 samples collected from boreholes extending to over $137 \mathrm{~m}$ bgs at sites at SNL/NM (SNL, 1996), a conservative estimate of the average native volumetric moisture content in the vadose zone below the MWL is approximately ten percent. At this moisture content, average unsaturated hydraulic conductivity $(K(\theta))$ values for the combined laboratory and IP field data sets are on the order of $10^{-11} \mathrm{~cm} / \mathrm{s}$, with maximum values on the order of $10^{-10} \mathrm{~cm} / \mathrm{s}$ (Figure 6).

\subsection{Conclusions}

Data sets combining laboratory and field data are superior to laboratory or field data sets alone. Modeling based on data from laboratory tests may under predict $\mathrm{K}(\theta)$ due to loss of structure, heterogeneity, or inaccurate boundary conditions. Field infiltration tests may accurately simulate small, short-term events such as spills, but may not reflect the full saturation and greater hydraulic conductivity associated with long-term leakage; for example, a failed settling-pond liner or leaking water line. When modeling soil moisture characteristics and unsaturated hydraulic conductivity data using the computer program RETC, the most accurate predictions of hydraulic conductivity are based on data sets that combine field and laboratory data.

Combining laboratory and field data expresses the full range and most accurate predictions of $\psi(\theta)$ and $K(\theta)$ relationships. RETC predictions of $K_{\text {eff }}$ through the near-surface vadose zone was 
predicted to be $4.6 \times 10^{-3} \mathrm{~cm} / \mathrm{s}$ using combined laboratory and IP field data, approximately one and one-half orders of magnitude greater than predictions based on field data alone $\left(8.6 \times 10^{-5}\right.$ $\mathrm{cm} / \mathrm{s}$ ), and more than three orders of magnitude greater than values measured in laboratory tests $\left(2.9 \times 10^{-6} \mathrm{~cm} / \mathrm{s}\right)$.

Comparing RETC predictions based on laboratory data with predictions based on field data illustrates the apparent influence of in situ field-scale structure and preferential flow. The higher predicted values of $\mathrm{K}_{\mathrm{s}}$ based on field data alone compared to simulations derived from laboratory data alone suggest that soil structure not investigated during testing of laboratory samples may contribute to preferential flow when soil moisture contents approach saturation (Figure 4).

At the approximate native moisture contents existing in the vadose zone below the MWL $\left(\theta_{\mathrm{v}} \cong\right.$ $0.10)$, RETC predictions of maximum and average $K(\theta)$ based on either field data, laboratory data, or combined laboratory and field data are all on the order of $10^{-10} \mathrm{~cm} / \mathrm{s}$ (see Figures 4 and 6). Assuming a unit gradient with depth and a maximum unsaturated hydraulic conductivity of $10^{-10} \mathrm{~cm} / \mathrm{s}$, the maximum steady-state areal recharge rate in the vicinity of the MWL is calculated to be $10^{-10} \mathrm{~cm} / \mathrm{s}\left(1.2 \times 10^{-3}\right.$ inches per year). This is approximately $0.02 \%$ of the annual precipitation rate at SNL/NM, and implies that the potential for aqueous recharge through the vadose zone to groundwater is very low, exclusive of preferential flow. 


\subsection{References}

Bayliss, S., Goering, T. J., McVey, M. D., Strong, W. R., and J. L. Peace. 1996. Preliminary Data from an Instantaneous Profile Test Conducted Near the Mixed Waste Landfill, Technical Area 3, Sandia National Laboratories/New Mexico. SAND96-0813

Carsel, R. F. and R. S. Parrish. 1988. Developing joint probability distributions of soil water retention characteristics. Water Resour. Res. vol. 24.

Crowson, D., Gibson, J. D., Haase, C. S., Holt, R., Hyndman, D., Krumhansl, J., Lauffer, F., McCord, J. P., McCord, J. T., Neel, D., Parsons, A. M., and R. Thomas. 1993. SNL SiteWide Hydrogeologic Characterization Project Calendar Year 1992 Annual Report. SNL, Albuquerque, NM.

Freeze, R. A. , and Cherry, J. A., (1979), Groundwater, Prentice-Hall, Inc, Englewood Cliffs, New Jersey.

Goering, T. J., McVey, M. D., Strong, W. R., Nguyen, H. A., and J. L. Peace. 1995. Analysis of Instantaneous Profile Test Data from Soils Near the Mixed Waste Landfill, Technical Area 3, Sandia National Laboratories/New Mexico. Sand Report Sand95-1637. Sandia National Laboratories, Albuquerque, New Mexico.

Hillel, D., Krentos, V. D., and Y. Stylianou. 1972. Procedure and test of an internal drainage method for measuring soil hydraulic characteristics in situ. Soil Science. vol. 114, No. 5.

Klute, A. (ed). Methods of Soil Analysis, Part I, Physical and Mineralogical Methods. 1986. 2nd Edition, Soil Science Society of America, Inc. Madison, WI.

Marion, J. M., Or, D., Rolston, D. E., Kavvas, M. L., and J. W. Biggar. 1994. Evaluation of Methods for Determining Soil-Water Retentivity and Unsaturated Hydraulic Conductivity. Soil Science. Vol. 158, No. 1.

Rawls, W. J., Brackensiek, D. L., and K. E. Saxton. 1982. Estimating soil water properties. Transactions, ASAE. vol. 25(5).

SNL. 1993. Mixed Waste Landfill Phase 2 RCRA Facility Investigation Work Plan. Prepared by Sandia National Laboratory Environmental Restoration Program for the United States Department of Energy, Albuquerque Operations Office.

SNL. 1996. SWHC 1995 Calendar Year Annual Report. Environmental Restoration Project, DOE, Albuquerque Operations Office.

Van Genuchten, M. Th., Leij, F. J., and S. R. Yates. 1994. RETC: Quantifying the hydraulic functions of unsaturated soils. Computer program IGWMC-FOS 55. International Groundwater Modeling Center, Golden, CO. 
Tables

Table 1. RETC-derived parameters from $\psi(\theta)$ data of laboratory-tested samples. $\mathrm{K}_{\mathrm{s}}$ and $l$ were fixed at laboratory-measured values in these simulations.

\begin{tabular}{|c|c|c|c|c|c|c|c|c|c|}
\hline Sample & $\begin{array}{l}\text { Average } \\
\text { Depth (cm) }\end{array}$ & $\left|\begin{array}{l}\text { WCR } \\
\left(\mathrm{cm}^{3} / \mathrm{cm}^{3}\right)\end{array}\right|$ & \begin{tabular}{|l|} 
WCS \\
$\left(\mathrm{cm}^{3} / \mathrm{cm}^{3}\right)$
\end{tabular} & $\begin{array}{l}\alpha \\
(1 / \mathrm{cm})\end{array}$ & $\begin{array}{l}\mathbf{n} \\
(-)\end{array}$ & $\begin{array}{l}m \\
(-)\end{array}$ & $l$ & $\begin{array}{l}\mathrm{K}_{s}, \mathbf{R E T} \\
(\mathrm{cm} / \mathrm{s})\end{array}$ & $\mathbf{R}^{2}$ \\
\hline $\mathrm{IP}-300$ & 0.8 & 0.05 & 0.38 & 0.008 & 1.35 & $=1-1 / n$ & 0.50 & $3.0 \mathrm{E}-04$ & 0.957 \\
\hline $\mathrm{IP}-301$ & 23.0 & 0.04 & 0.40 & 0.150 & 1.36 & $=1-1 / n$ & 0.50 & $1.0 \mathrm{E}-04$ & 0.994 \\
\hline IP-302 & 35.5 & 0.07 & 0.43 & 0.017 & 1.33 & $=1-1 / \mathrm{n}$ & 0.50 & $1.0 \mathrm{E}-04$ & 0.980 \\
\hline IP-303 & 45.5 & 0.14 & 0.39 & 0.014 & 1.42 & $=1-1 / \mathrm{n}$ & 0.50 & $3.0 \mathrm{E}-04$ & 0.983 \\
\hline IP-304 & 66.6 & 0.09 & 0.38 & 0.015 & 1.55 & $=1-1 / n$ & 0.50 & $3.0 \mathrm{E}-04$ & 0.990 \\
\hline IP-305 & 76.5 & 0.06 & 0.35 & 0.019 & 1.39 & $=1-1 / n$ & 0.50 & $1.0 \mathrm{E}-04$ & 0.996 \\
\hline IP-306 & 86.5 & 0.06 & 0.32 & 0.012 & 1.01 & 0.18 & 0.50 & $2.0 \mathrm{E}-05$ & 0.981 \\
\hline IP-307 & 96.5 & 0.17 & 0.35 & * & 1.21 & $=1-1 / n$ & 0.50 & $7.0 \mathrm{E}-07$ & 0.923 \\
\hline IP-308 & 106.5 & 0.08 & 0.41 & 0.013 & 1.41 & $=1-1 / n$ & 0.50 & $7.0 \mathrm{E}-05$ & 0.996 \\
\hline IP-309 & 137.5 & 0.08 & 0.31 & 0.005 & 1.22 & $=1-1 / n$ & 0.50 & $2.0 \mathrm{E}-06$ & 0.982 \\
\hline $\mathrm{PP}-310$ & 147.5 & 0.04 & 0.33 & 0.014 & 1.19 & $=1-1 / \mathrm{n}$ & 0.50 & $3.0 \mathrm{E}-06$ & 0.986 \\
\hline $\mathrm{IP}-311$ & 158.5 & 0.10 & 0.35 & 0.160 & 1.14 & $=1-1 / n$ & 0.50 & $2.0 \mathrm{E}-07$ & 0.920 \\
\hline $\mathrm{IP}-312$ & 167.5 & 0.11 & 0.45 & 0.014 & 1.07 & $=1-1 / n$ & 0.50 & $4.0 \mathrm{E}-05$ & 0.997 \\
\hline IP-313 & 179.0 & 0.11 & 0.42 & * & 1.48 & $=1-1 / n$ & 0.50 & 3.0E-04 & 0.956 \\
\hline IP-314 & 188.0 & 0.05 & 0.35 & 0.005 & 1.26 & $=1-1 / \mathrm{n}$ & 0.50 & $3.0 \mathrm{E}-04$ & 0.986 \\
\hline $\mathrm{IP}-315$ & 203.5 & 0.06 & 0.45 & 0.019 & 1.33 & $=1-1 / n$ & 0.50 & $3.0 \mathrm{E}-05$ & 0.998 \\
\hline IP-318 & 228.5 & 0.03 & 0.45 & 0.019 & 1.01 & $=1-1 / n$ & 0.50 & $2.0 \mathrm{E}-05$ & 0.996 \\
\hline IP-320 & 261.5 & 0.08 & 0.37 & 0.012 & 1.69 & 0.33 & 0.50 & $1.0 \mathrm{E}-04$ & 0.997 \\
\hline
\end{tabular}

$\begin{array}{cllllll} & \underline{\mathbf{W C R}} & \underline{\mathbf{W C S}} & \underline{\boldsymbol{\alpha}} & \underline{\mathbf{n}} & \underline{\mathbf{m}} & \underline{\underline{\mathbf{K}}} \\ \text { Minimum } & 0.030 & 0.310 & 0.005 & 1.010 & 0.180 & 2.0 \mathrm{E}-07 \\ \text { Maximum: } & 0.170 & 0.450 & 0.160 & 1.690 & 0.327 & 3.0 \mathrm{E}-04 \\ \text { Average: } & 0.079 & 0.383 & 0.031 & 1.301 & 0.254 & 1.2 \mathrm{E}-04 \\ \text { Deviation: } & 0.037 & 0.045 & 0.049 & 0.182 & 0.104 & 1.2 \mathrm{E}-04\end{array}$

* RETC could not fit a reasonable value 
Table 2. RETC-derived parameters from in situ $K(\theta)$ data derived during the IP test. Because $K(\theta)$ data does not reflect air entry pressures, the van Genuchten parameter related to air entry pressure, $\alpha$, was necessarily fixed.

\begin{tabular}{|l|l|l|l|l|l|l|l|l|l|}
\hline Sample & $\begin{array}{l}\text { Average } \\
\text { Depth }(\mathrm{cm})\end{array}$ & $\begin{array}{l}\text { WCR } \\
\left(\mathrm{cm}^{3} / \mathrm{cm}^{3}\right)\end{array}$ & $\begin{array}{l}\text { WCS } \\
\left(\mathbf{c m}^{3} / \mathrm{cm}^{3}\right)\end{array}$ & $\begin{array}{l}\alpha \\
(1 / \mathrm{cm})\end{array}$ & $\begin{array}{l}\mathbf{n} \\
(-)\end{array}$ & $\begin{array}{l}\mathbf{m} \\
(-)\end{array}$ & $\begin{array}{l}l \\
(-)\end{array}$ & $\begin{array}{l}\mathbf{K}_{\mathbf{s}} \\
(\mathbf{c m} / \mathbf{s})\end{array}$ & $\mathbf{R}^{2}$ \\
\hline $015-045 \mathrm{~s}$ & 30 & 0.05 & 0.24 & 0.013 & 1.39 & $=1-1 / \mathrm{n}$ & 0.50 & $2.3 \mathrm{E}-05$ & 0.951 \\
\hline $045-075 \mathrm{~s}$ & 60 & 0.07 & 0.28 & 0.010 & 1.42 & $=1-1 / \mathrm{n}$ & 0.50 & $2.0 \mathrm{E}-04$ & 0.994 \\
\hline $075-105 \mathrm{~s}$ & 90 & 0.08 & 0.31 & 0.010 & 1.74 & $=1-1 / \mathrm{n}$ & 0.50 & $1.0 \mathrm{E}-04$ & 0.988 \\
\hline $105-135 \mathrm{~s}$ & 120 & 0.08 & 0.32 & 0.010 & 1.19 & $=1-1 / \mathrm{n}$ & 8.38 & $2.0 \mathrm{E}-03$ & 0.992 \\
\hline $135-165 \mathrm{~s}$ & 150 & 0.10 & 0.29 & 0.010 & 1.41 & $=1-1 / \mathrm{n}$ & 0.50 & $1.0 \mathrm{E}-04$ & 0.985 \\
\hline $165-195 \mathrm{~s}$ & 180 & 0.10 & 0.42 & 0.010 & 1.40 & $=1-1 / \mathrm{n}$ & 0.50 & $9.0 \mathrm{E}-04$ & 0.987 \\
\hline
\end{tabular}

\begin{tabular}{|c|c|c|c|c|c|c|}
\hline & WCR & WCS & $\underline{\alpha}$ & $\underline{\mathbf{n}}$ & $\underline{\mathbf{m}}$ & $\underline{\mathbf{K}}$ \\
\hline Minimum & 0.037 & 0.045 & 0.010 & 0.182 & 0.104 & $2.3 \mathrm{E}-05$ \\
\hline Maximum: & 0.170 & 0.450 & 0.160 & 1.735 & 0.327 & $2.0 \mathrm{E}-03$ \\
\hline Average: & 0.085 & 0.304 & 0.034 & 1.303 & 0.228 & 4.3E-04 \\
\hline Standard De & 0.038 & 0.119 & 0.049 & 0.454 & 0.114 & $6.5 \mathrm{E}-04$ \\
\hline
\end{tabular}

Table 3. RETC-derived parameters from combined laboratory $\psi(\theta)$ and in situ $\mathbf{K}(q)$ data.

\begin{tabular}{|l|l|l|l|l|l|l|l|l|l|}
\hline Sample & $\begin{array}{l}\text { Average } \\
\text { Depth }(\mathrm{cm})\end{array}$ & $\begin{array}{l}\text { WCR } \\
\left(\mathrm{cm}^{3} / \mathrm{cm}^{3}\right)\end{array}$ & $\begin{array}{l}\text { WCS } \\
\left(\mathrm{cm}^{3} / \mathrm{cm}^{3}\right)\end{array}$ & $\begin{array}{l}\alpha \\
(1 / \mathrm{cm})\end{array}$ & $\begin{array}{l}\mathbf{n} \\
(-)\end{array}$ & $\begin{array}{l}\mathbf{m} \\
(-)\end{array}$ & $\begin{array}{l}l \\
(-)\end{array}$ & $\begin{array}{l}\mathbf{K}_{\mathbf{s}} \\
(\mathrm{cm} / \mathbf{s})\end{array}$ & $\mathbf{R}^{2}$ \\
\hline $015-045 \mathrm{~s}$ & 30 & 0.08 & 0.40 & 0.011 & 1.4299 & $1-1 / \mathrm{n}$ & 0.0001 & $6.1 \mathrm{E}-03$ & 0.996 \\
\hline $045-075 \mathrm{~s}$ & 60 & 0.08 & 0.38 & 0.015 & 1.47 & $1-1 / \mathbf{n}$ & 0.50 & $3.2 \mathrm{E}-03$ & 0.997 \\
\hline $075-105 \mathrm{~s}$ & 90 & 0.11 & 0.36 & 0.008 & 1.4216 & $1-1 / \mathbf{n}$ & 8.1144 & $2.4 \mathrm{E}-03$ & 0.996 \\
\hline $105-135 \mathrm{~s}$ & 120 & 0.07 & 0.36 & 0.029 & 1.2029 & $1-1 / \mathbf{n}$ & 4.039 & $5.5 \mathrm{E}-03$ & 0.993 \\
\hline $135-165 \mathrm{~s}$ & 150 & 0.08 & 0.36 & 0.046 & 1.381 & $1-1 / \mathbf{n}$ & 0.0008 & $7.5 \mathrm{E}-03$ & 0.992 \\
\hline $165-195 \mathrm{~s}$ & 180 & 0.10 & 0.40 & 0.066 & 1.2843 & $1-1 / \mathrm{n}$ & -3.7545 & $9.9 \mathrm{E}-03$ & 0.985 \\
\hline
\end{tabular}

\begin{tabular}{|c|c|c|c|c|c|c|}
\hline & WCR & WCS & $\underline{\alpha}$ & $\underline{\mathbf{n}}$ & $\underline{\mathbf{m}}$ & $\underline{\mathbf{K}}$ \\
\hline Minimum & 0.037 & 0.045 & 0.008 & 0.182 & 0.104 & 2.3E-05 \\
\hline Maximum: & 0.170 & 0.450 & 0.160 & 1.735 & 0.327 & $9.9 \mathrm{E}-03$ \\
\hline Average: & 0.084 & 0.316 & 0.043 & 1.186 & 0.193 & $3.8 \mathrm{E}-03$ \\
\hline Standard Dev & 0.038 & 0.130 & 0.045 & 0.483 & 0.106 & 3.3E-03 \\
\hline
\end{tabular}






Figure 1. Instantaneous profile test plot location. 


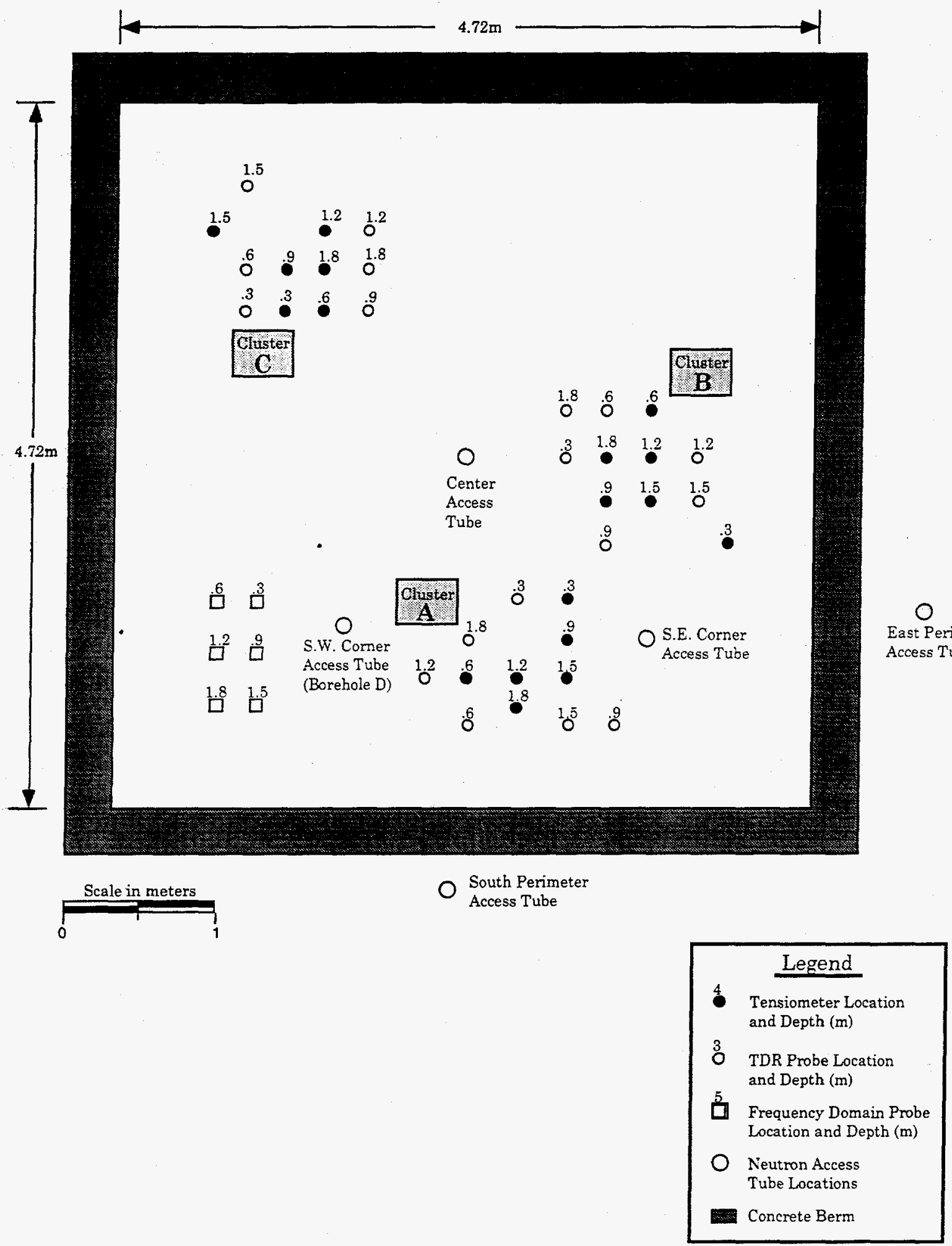

Figure 2. Instrument Locations in the IP test plot. Numbers above symbols indicate installation depth below ground surface. 


\section{Saturated Hydraulic Conductivity}

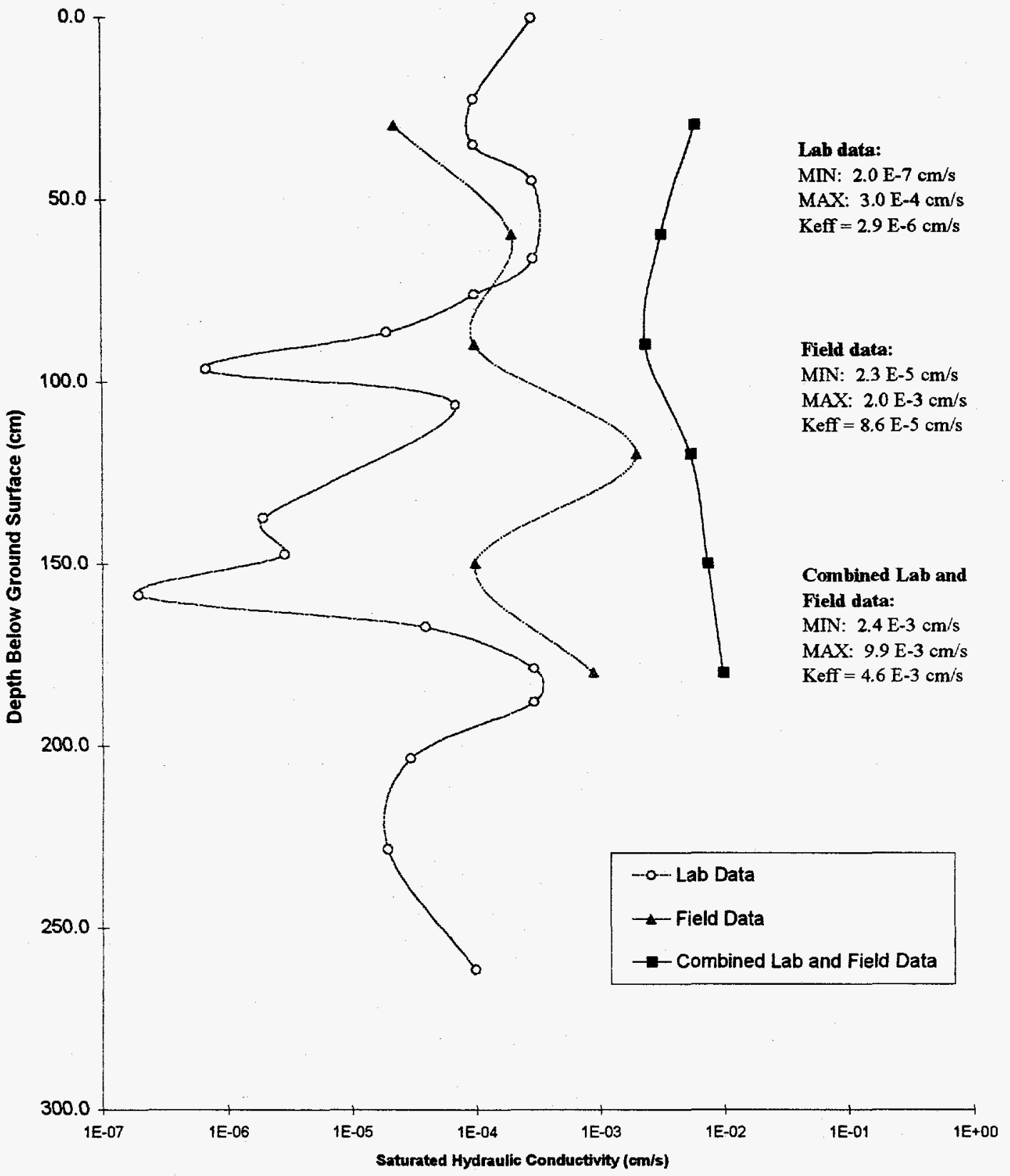

Figure 3. Saturated hydraulic conductivity with depth. Note that the average predicted value from the combined laboratory and IP field data exceeds that from field data alone by more than an order of magnitude and exceeds laboratory values by three orders of magnitude. 


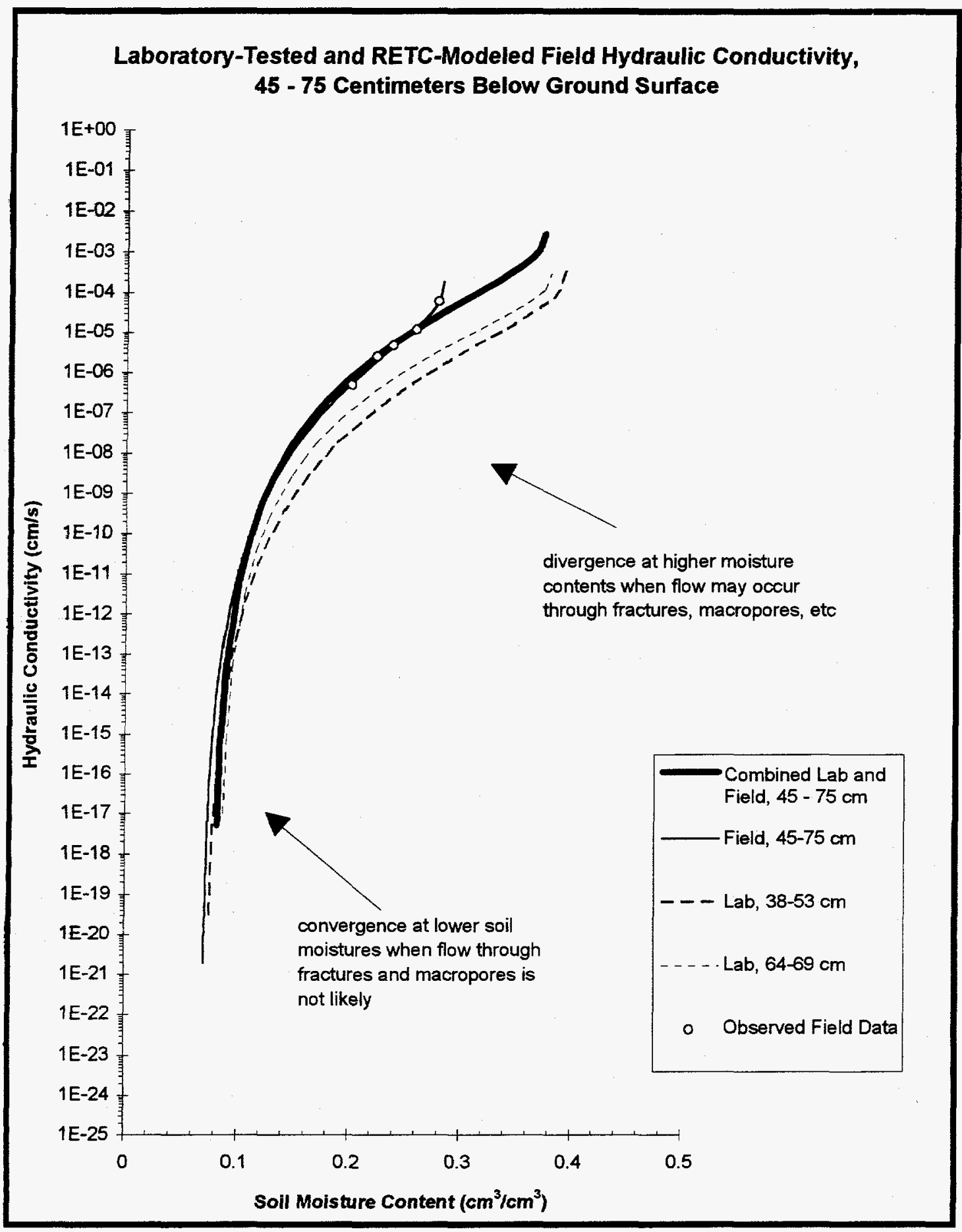

Figure 4. RETC-predicted hydraulic conductivity-moisture content relationships based on field, laboratory, and combined field and laboratory data. Lower hydraulic conductivity values from laboratory testing are observed at higher moisture contents. The divergence at higher moisture contents and the convergence at lower moisture contents suggests that preferential flow though soil structure (macropores and fractures) may occur if moisture contents approach saturation. 


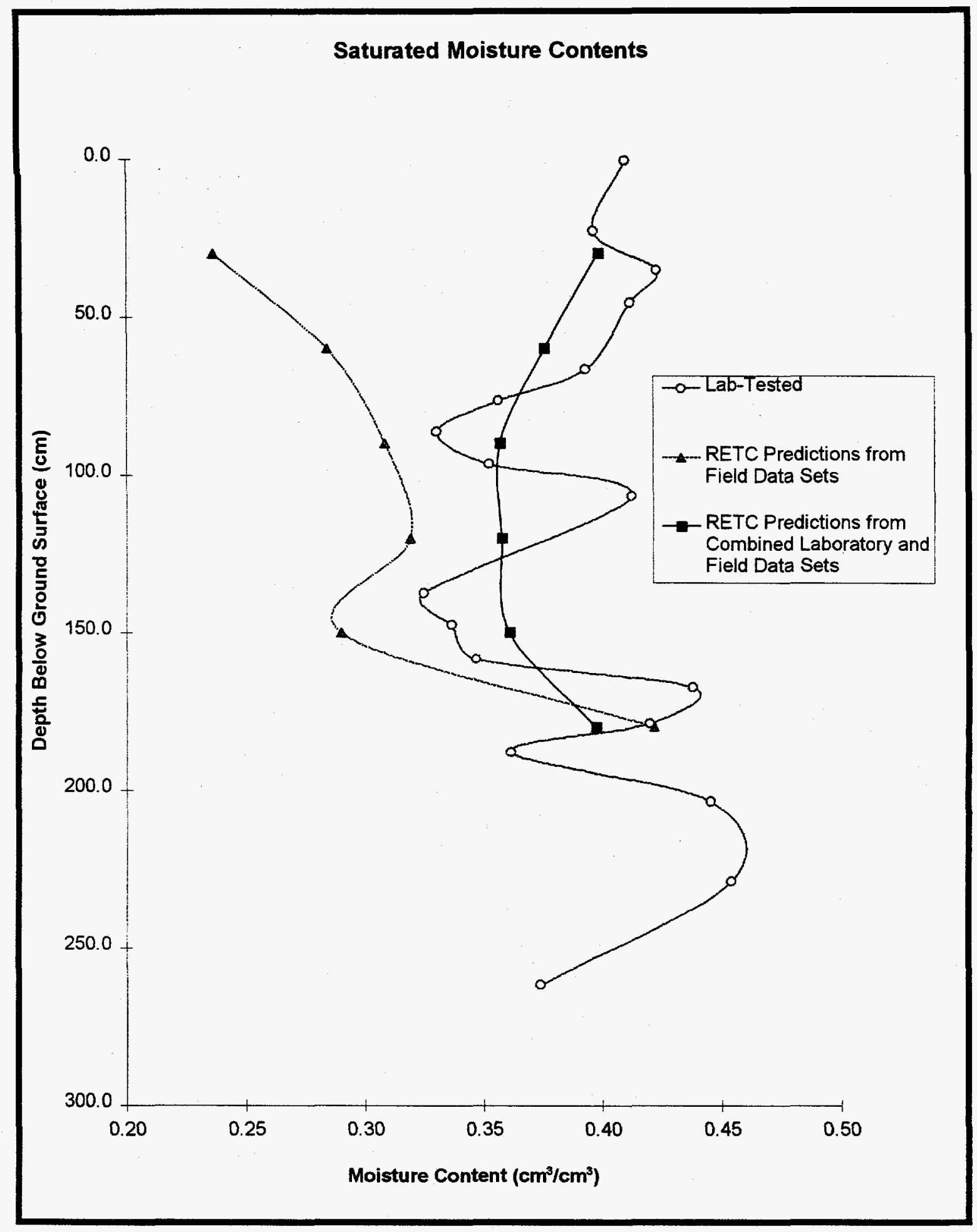

Figure 5. Laboratory-tested and RETC prediction of saturated moisture content based on IP field and combined field and laboratory data sets. Note that for all but the deepest interval, saturated moisture contents are least for field data. This yielded lower RETC predictions of saturated hydraulic conductivity from field data (see Figure 3). 


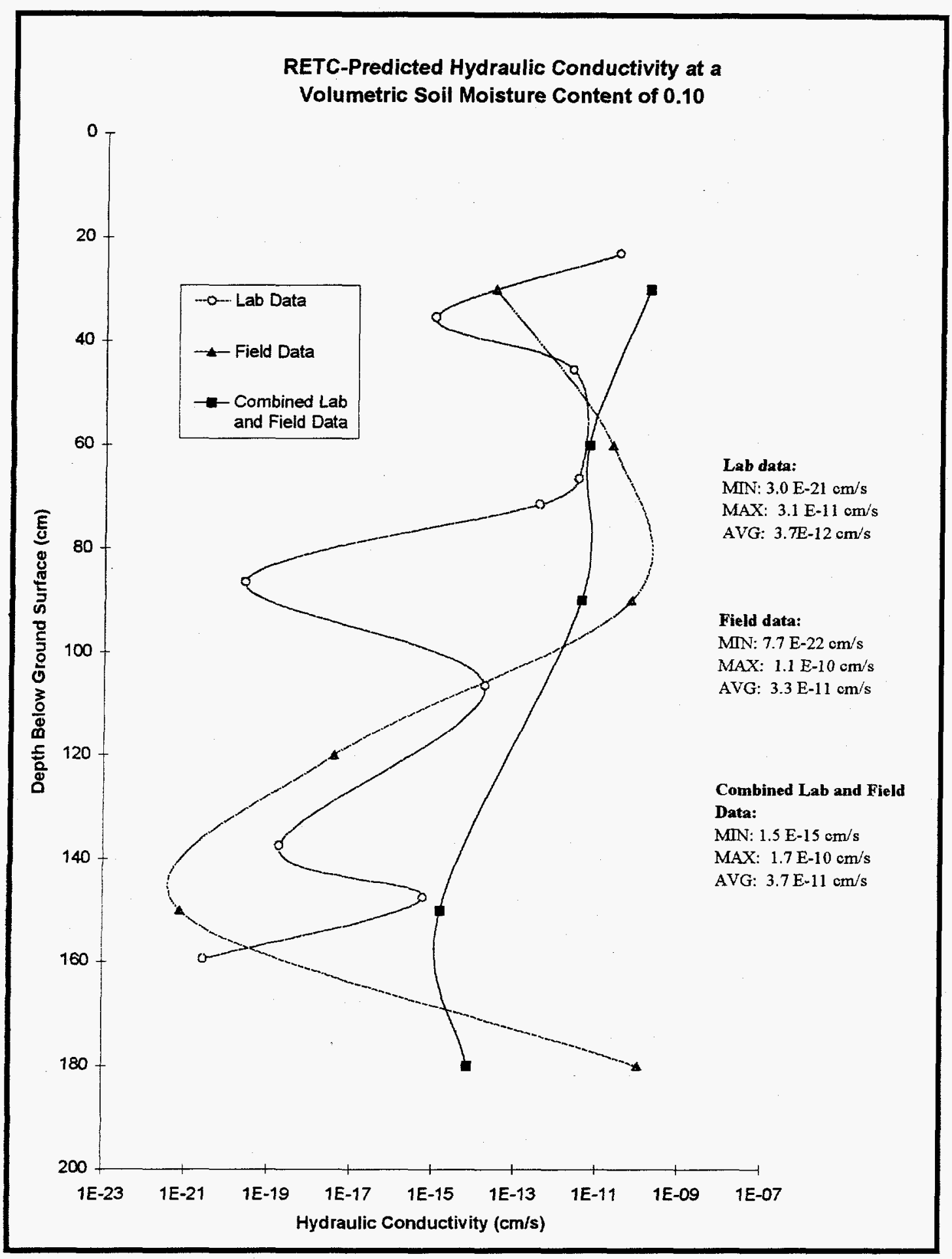

Figure 6. Hydraulic conductivity profile at a volumetric moisture content of 10 percent. At a volumetric moisture content of ten percent, the differences between RETC predictions from the three data sets are less definite that at saturated moisture contents (Figure 3). Regardless of the data set used, the predicted hydraulic conductivity is of so low a magnitude that aqueous transport from the MWL to groundwater is unlikely. 


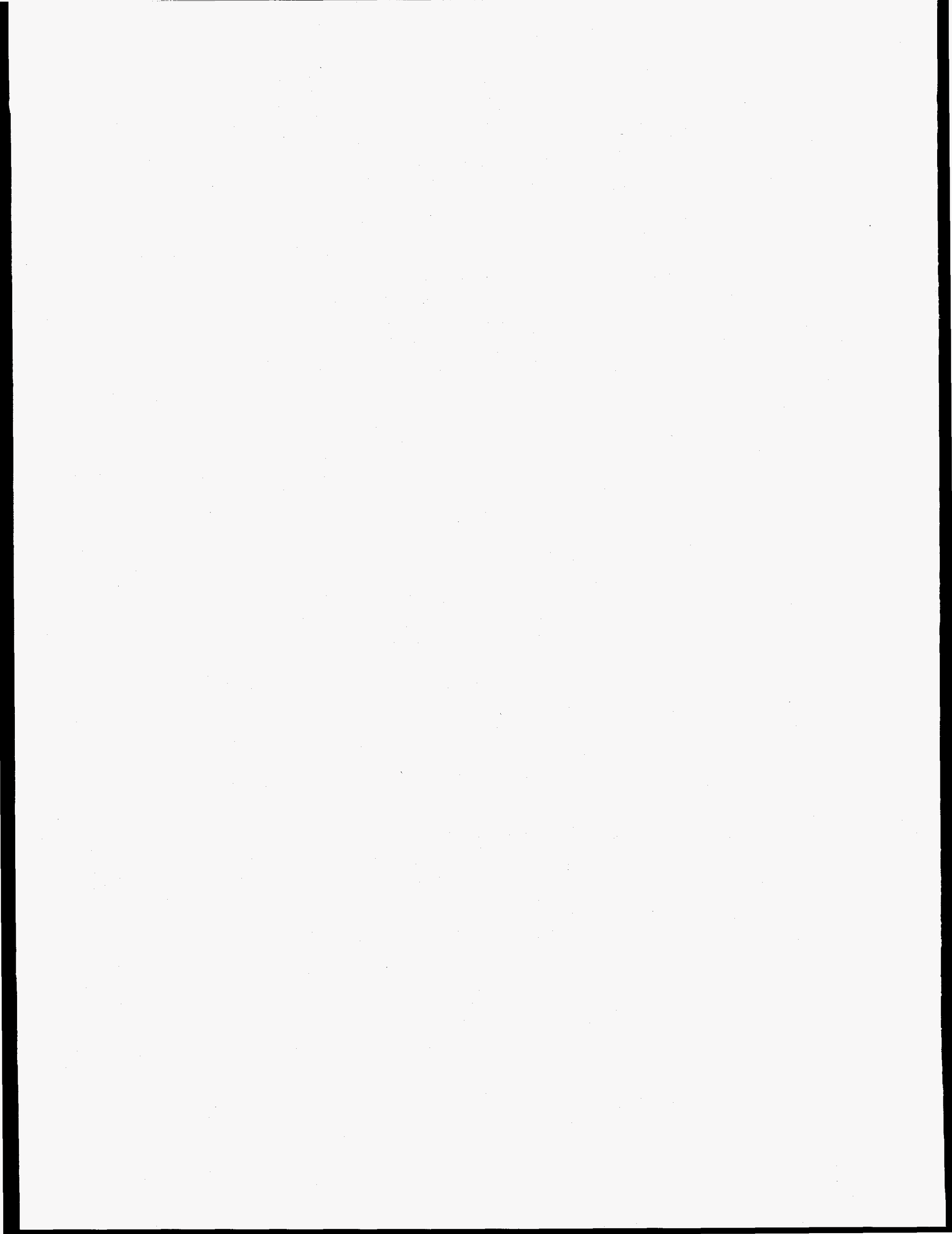




\section{APPENDIX A}

\section{RETC Predictions of $\psi(\theta)$ and $K(\theta)$ Relationships for Soils in the Vadose Zone Near the Mixed Waste Landfill}

\section{Contents}

Section 1.0 Graphs of $\psi(\theta)$ and $K(\theta)$ relationships based on laboratory testing of samples

Section 2.0 Graphs of $K(\theta)$ relationships based on data collected in situ during the Instantaneous Profile (IP) test

Section 3.0 Graphs of $K(\theta)$ relationships based on combined laboratory and field data

All graphs represent predictions made using the RETC computer code (van Genuchten et al., 1994). Field data were obtained during the Sandia National Laboratories/New Mexico Mixed Waste Landfill Instantaneous Profile Test (Goering et al., 1995).

\section{References}

Goering, T. J., McVey, M. D., Strong, W. R., Nguyen, H. A., and J. L. Peace. 1995. Analysis of Instantaneous Profile Test Data from Soils Near the Mixed Waste Landfill, Technical Area 3, Sandia National Laboratories/New Mexico. Sand Report Sand951637. Sandia National Laboratories, Albuquerque, New Mexico.

Van Genuchten, M. Th., Leij, F. J., and S. R. Yates. 1994. RETC: Quantifying the hydraulic functions of unsaturated soils. Computer program IGWMC-FOS 55. International Groundwater Modeling Center, Golden, CO. 


\section{Section 1.0 Graphs of RETC $\psi(\theta)$ and $K(\theta)$ relationships from data derived from laboratory testing of samples}

RETC simulations of soil moisture retention relationships are presented in this section. The RETC fits of lab $\psi(\theta)$ data for a sample are presented, along with graphs of the RETC predictions of the $K(\theta)$ relationship for that same sample, on pages A-3 through A-20. The results for the eighteen samples tested are shown. Samples are presented in order of increasing depth.

Sample number (e.g., IP 300), depth, R-squared value for the fit, and van Genuchten parameters are noted for each sample. If during the fitting process, it was necessary to fix a parameter value, its fixed value is noted; e.g., "WCR: 0.05 ." If the RETC program was allowed to fit the parameter value, both the initial estimate used and the final fitted value are shown. For example, "WCR: $0.05=>0.11$ " indicates that the program fitted a final volumetric residual moisture content value of 0.11 from an initial estimate of 0.05 .

\section{Nomenclature}

$\begin{array}{ll}\text { Rsq } & \text { the R-squared value for the fit. } \\ \text { WCR } & \text { residual volumetric moisture content. }\left[\mathrm{L}^{3} / \mathrm{L}^{3}\right] \\ \text { WCS } & \text { saturated soil moisture content. }\left[\mathrm{L}^{3} / \mathrm{L}^{3}\right] \\ \alpha & \text { the van Genuchten parameter related to the air entry pressure. [1/L] } \\ \mathrm{n} & \text { the " } \mathrm{n} \text { " van Genuchten fitting parameter. [ - ] } \\ \mathrm{m} & \text { the " } \mathrm{m} \text { ". van Genuchten fitting parameter. [ - ] } \\ 1 & \text { the "l" van Genuchten parameter. [ - ] } \\ \mathrm{K}_{\mathrm{s}} & \text { saturated hydraulic conductivity. [L/T] } \\ \mathrm{K}(\theta) & \begin{array}{l}\text { unsaturated hydraulic conductivity as a function of soil moisture } \\ \text { content. [L/T] }\end{array} \\ \psi(\theta): & \begin{array}{l}\text { the model used by the RETC program to predict the soil matric } \\ \text { tension/soil moisture content relationship. "van" denotes the van }\end{array} \\ & \begin{array}{l}\text { Genuchten solution, "B.C." indicates the Brooks/Corey model was } \\ \text { used. }\end{array} \\ \mathrm{K}(\psi): & \begin{array}{l}\text { the model used to predict the unsaturated hydraulic conductivity. } \\ \text { "Mualem" indicates the Mualem model was used. "Burdine" }\end{array} \\ \text { indicates that the Burdine model was used. }\end{array}$



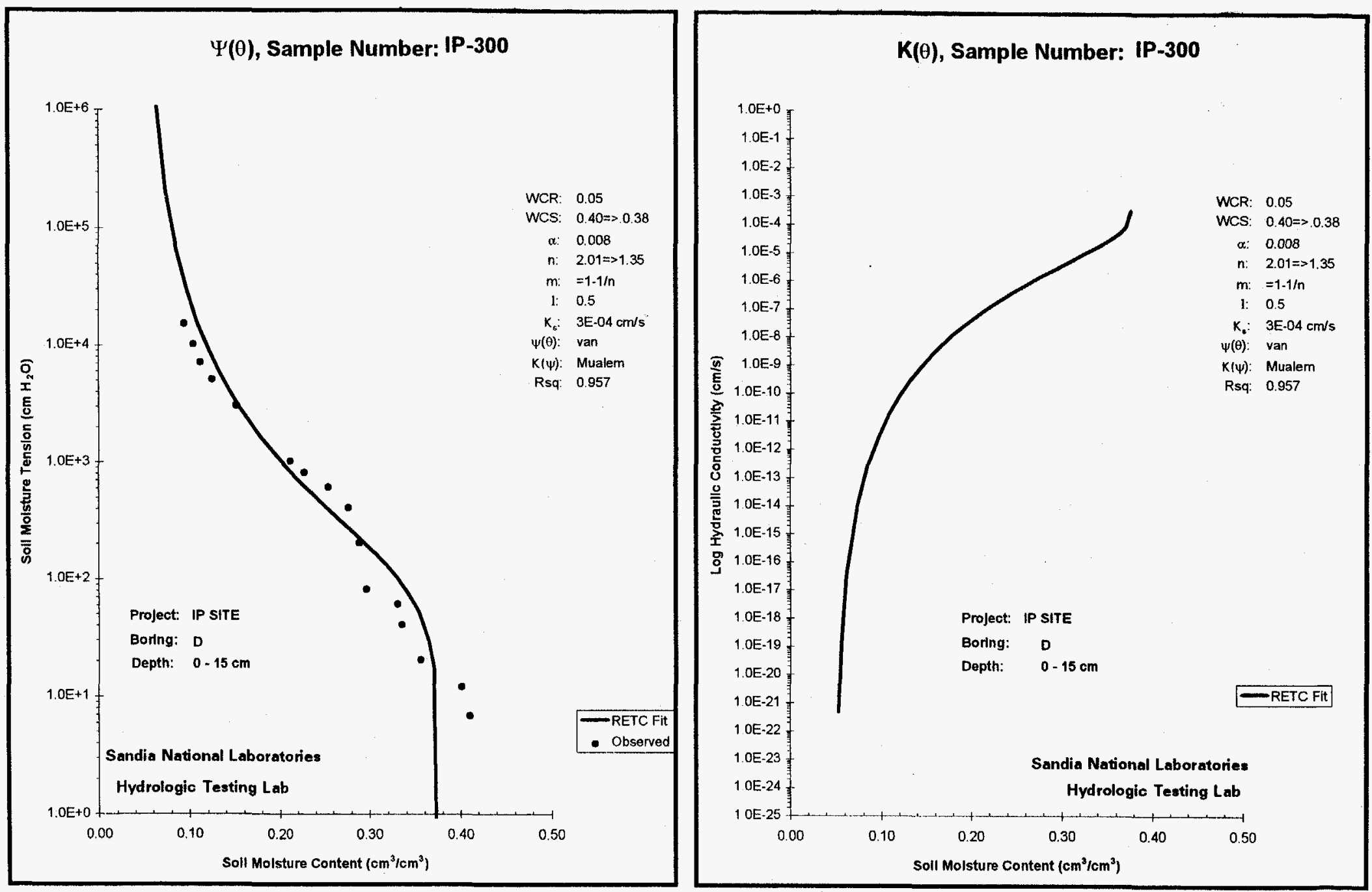

Figure A-1. RETC simulations of $\psi(\theta)$ and $K(\theta)$ relationships for the laboratory-tested sample from $0-15 \mathrm{~cm}$ bgs. 

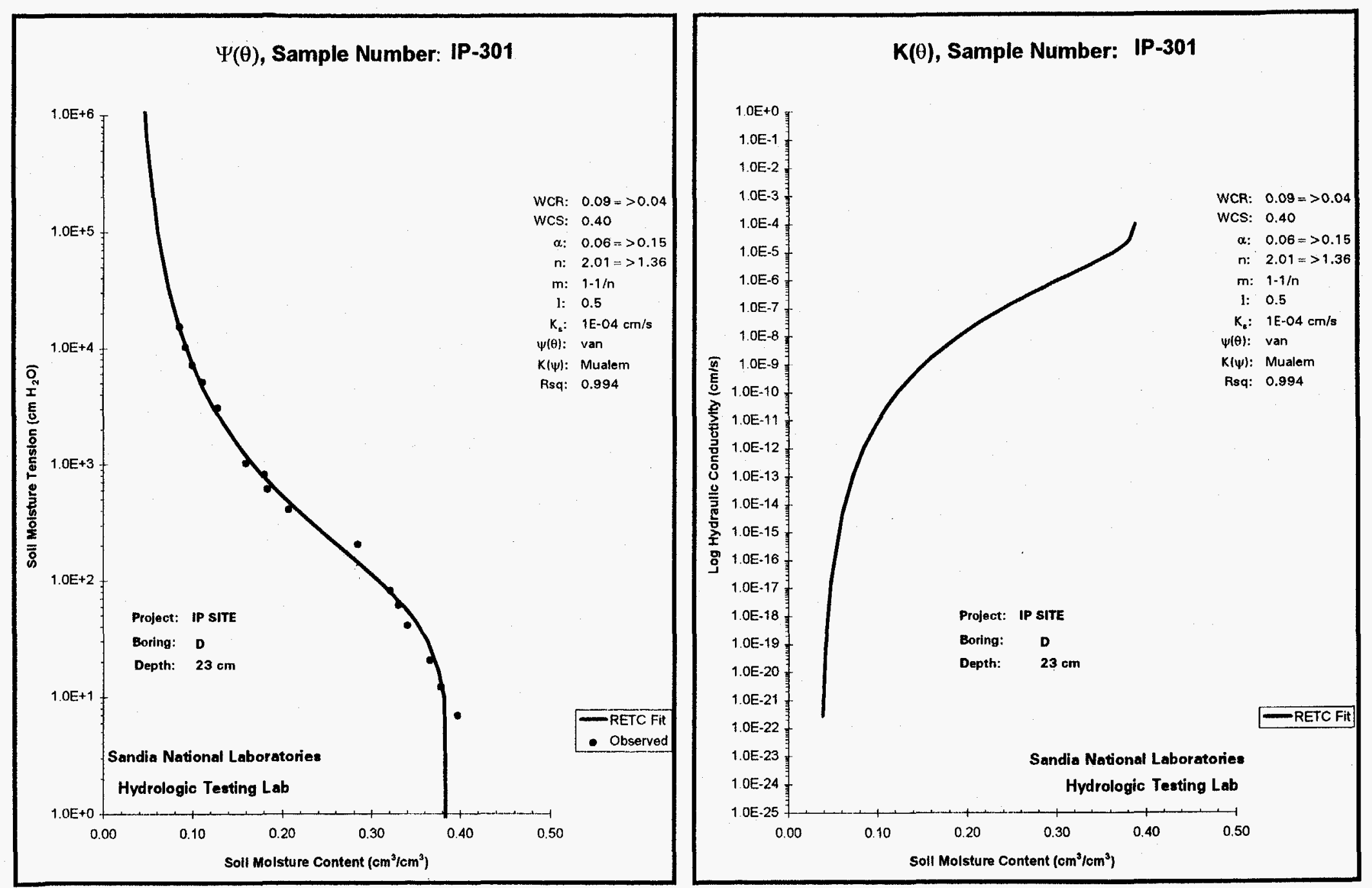

Figure A-2. RETC simulations of $\psi(\theta)$ and $K(\theta)$ relationships for the laboratory-tested sample from $33 \mathrm{~cm}$ bgs. 


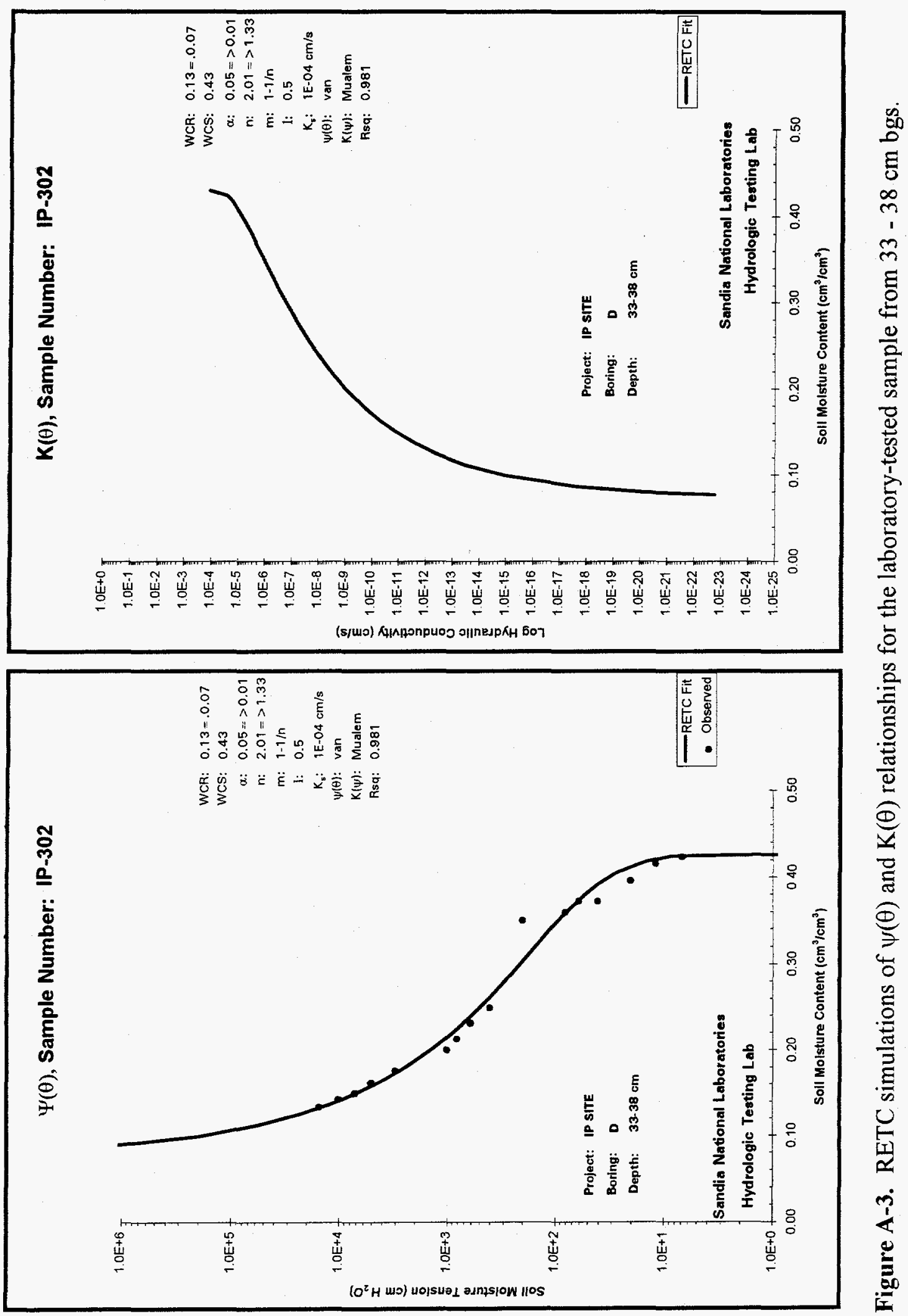




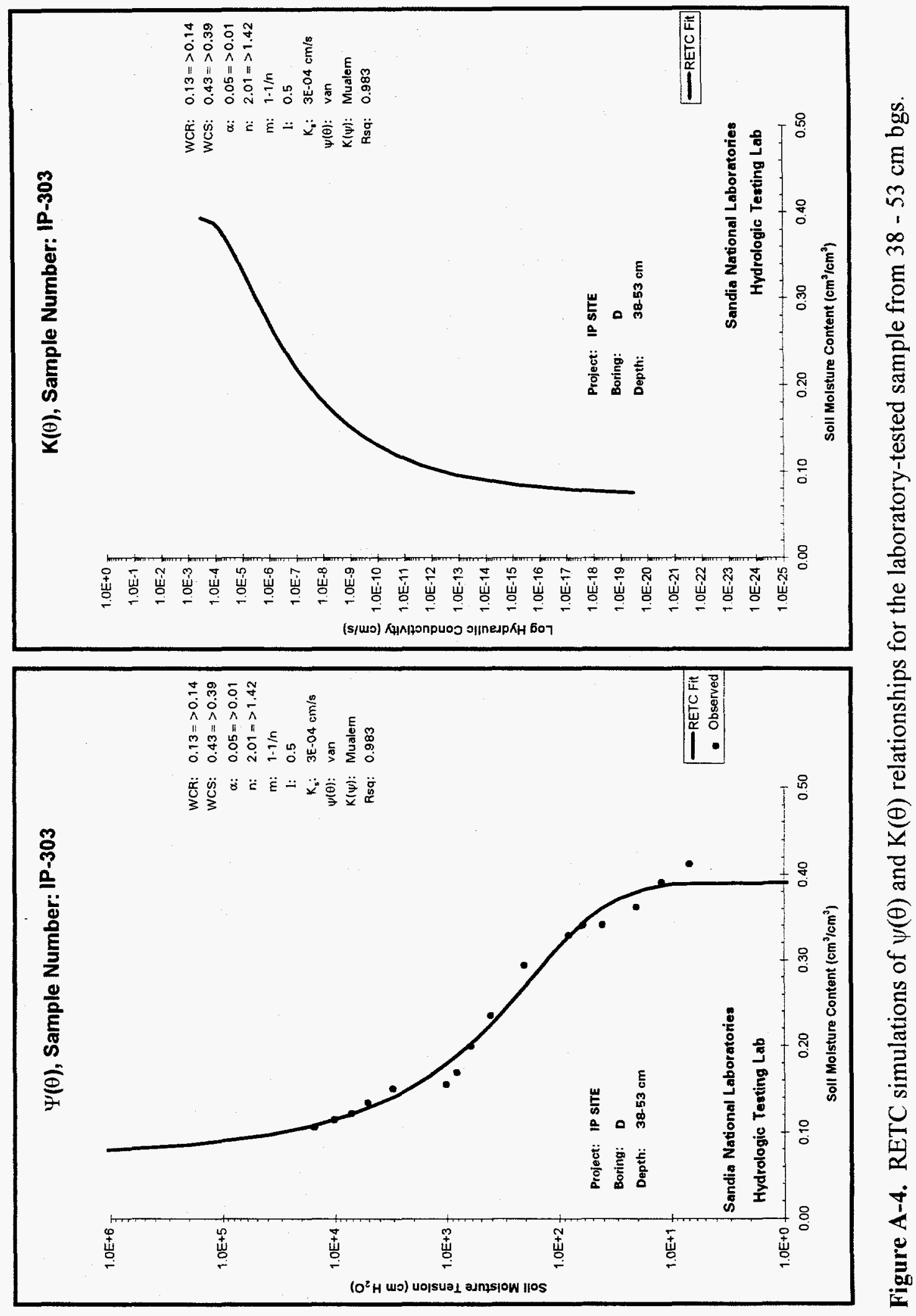



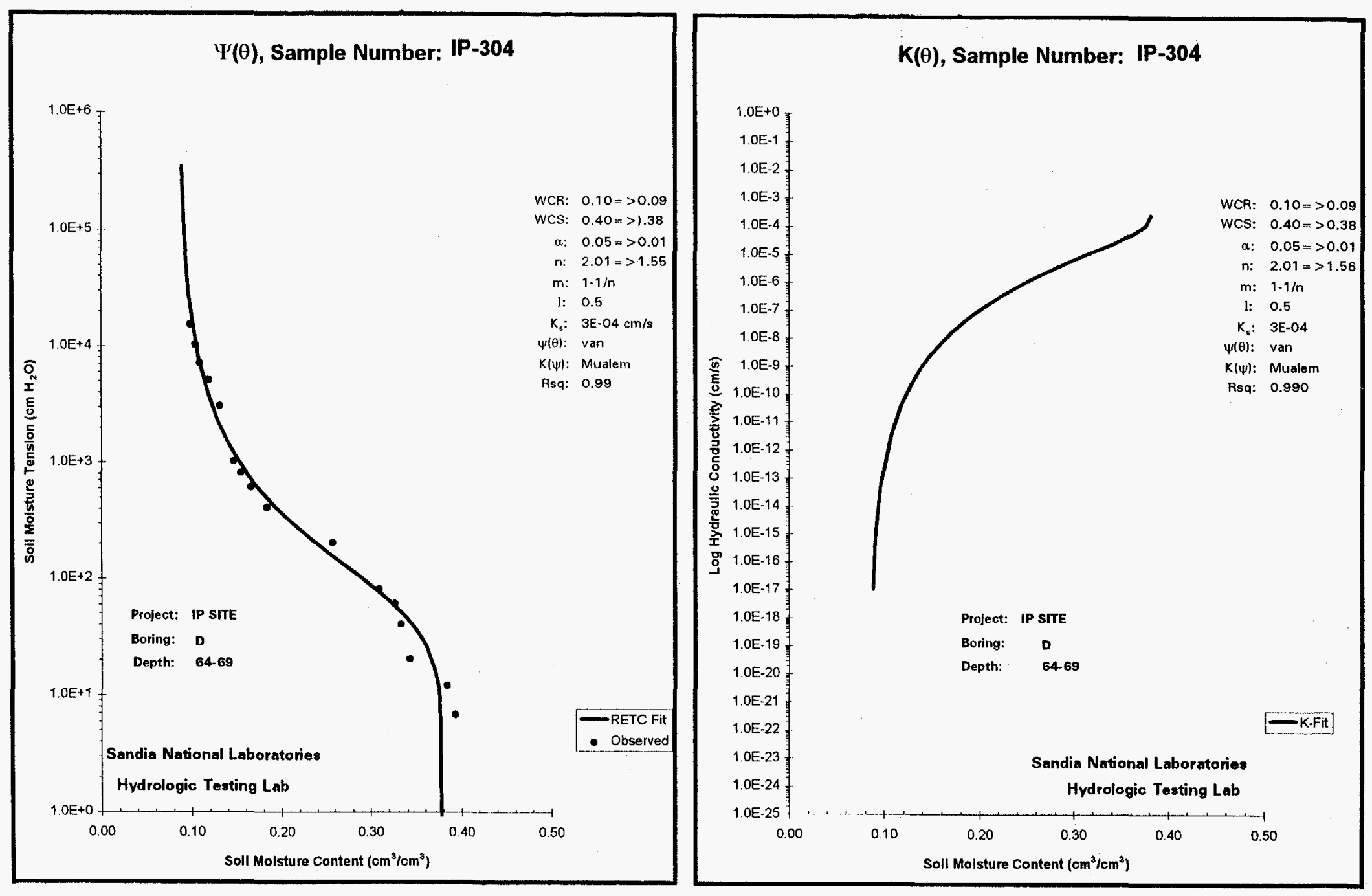

Figure A-5. RETC simulations of $\psi(\theta)$ and $K(\theta)$ relationships for the laboratory-tested sample from $64-69 \mathrm{~cm}$ bgs. 

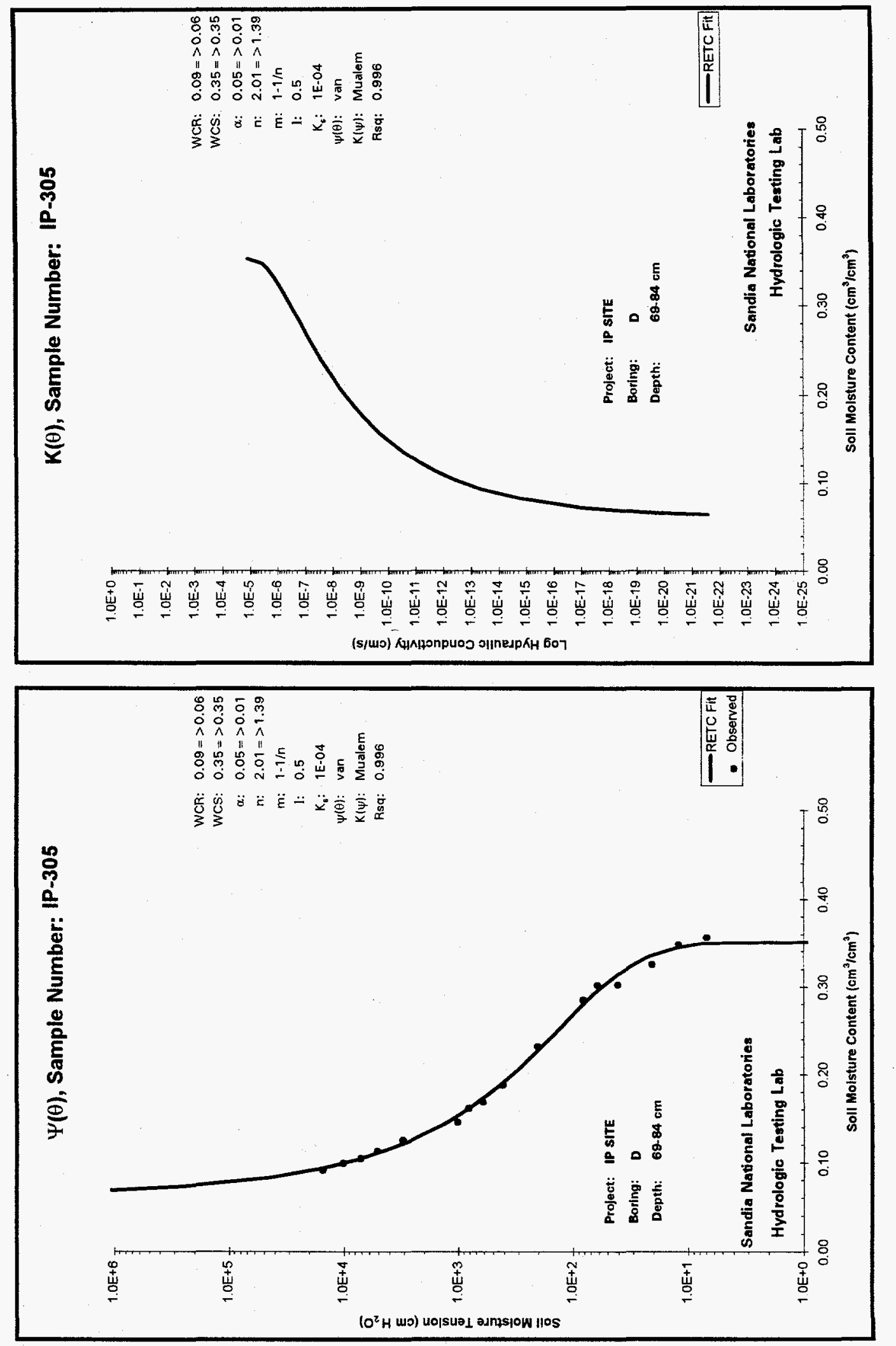

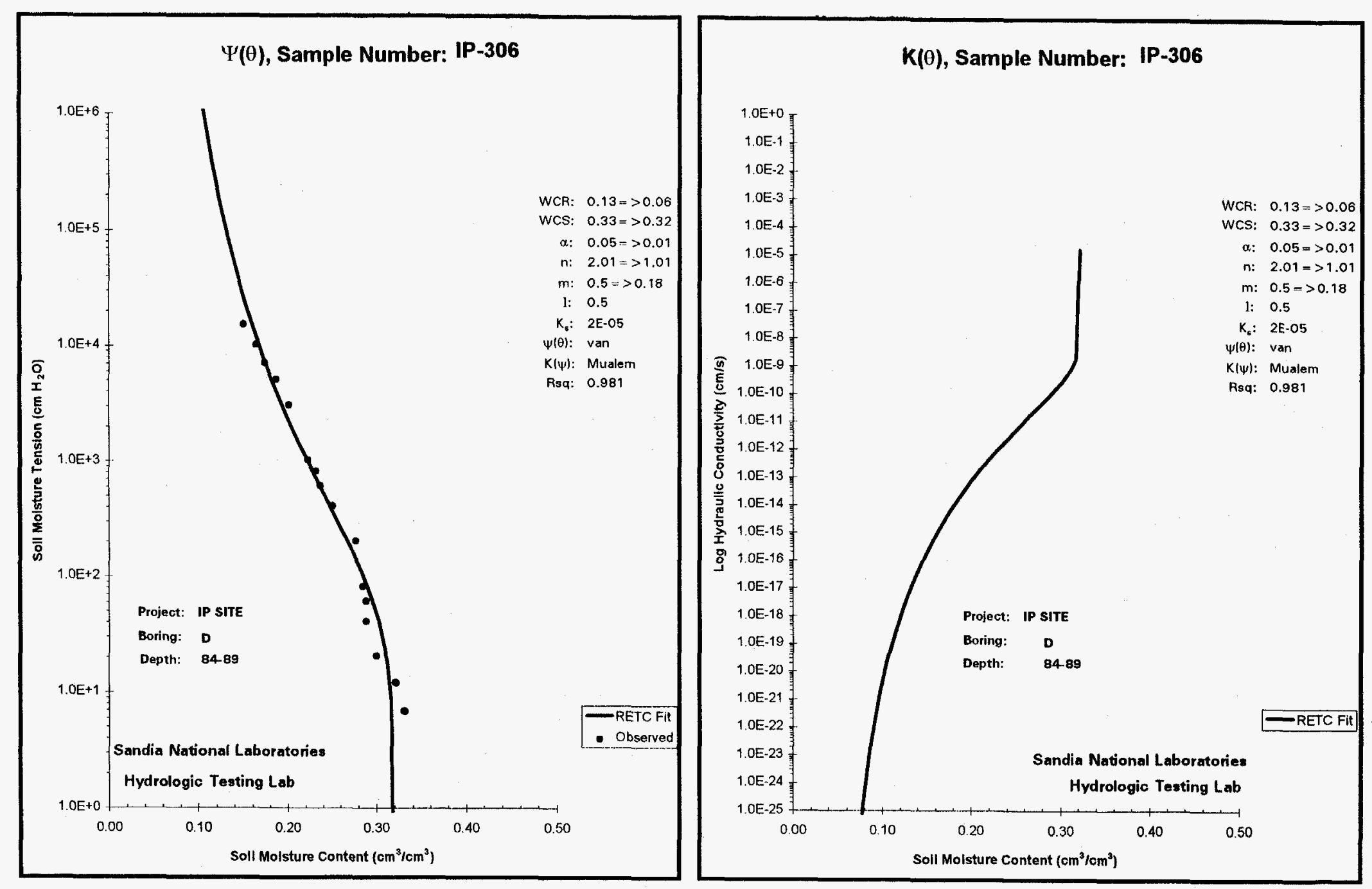

Figure A-7. RETC simulations of $\psi(\theta)$ and $K(\theta)$ relationships for the laboratory-tested sample from $84-89 \mathrm{~cm}$ bgs. 

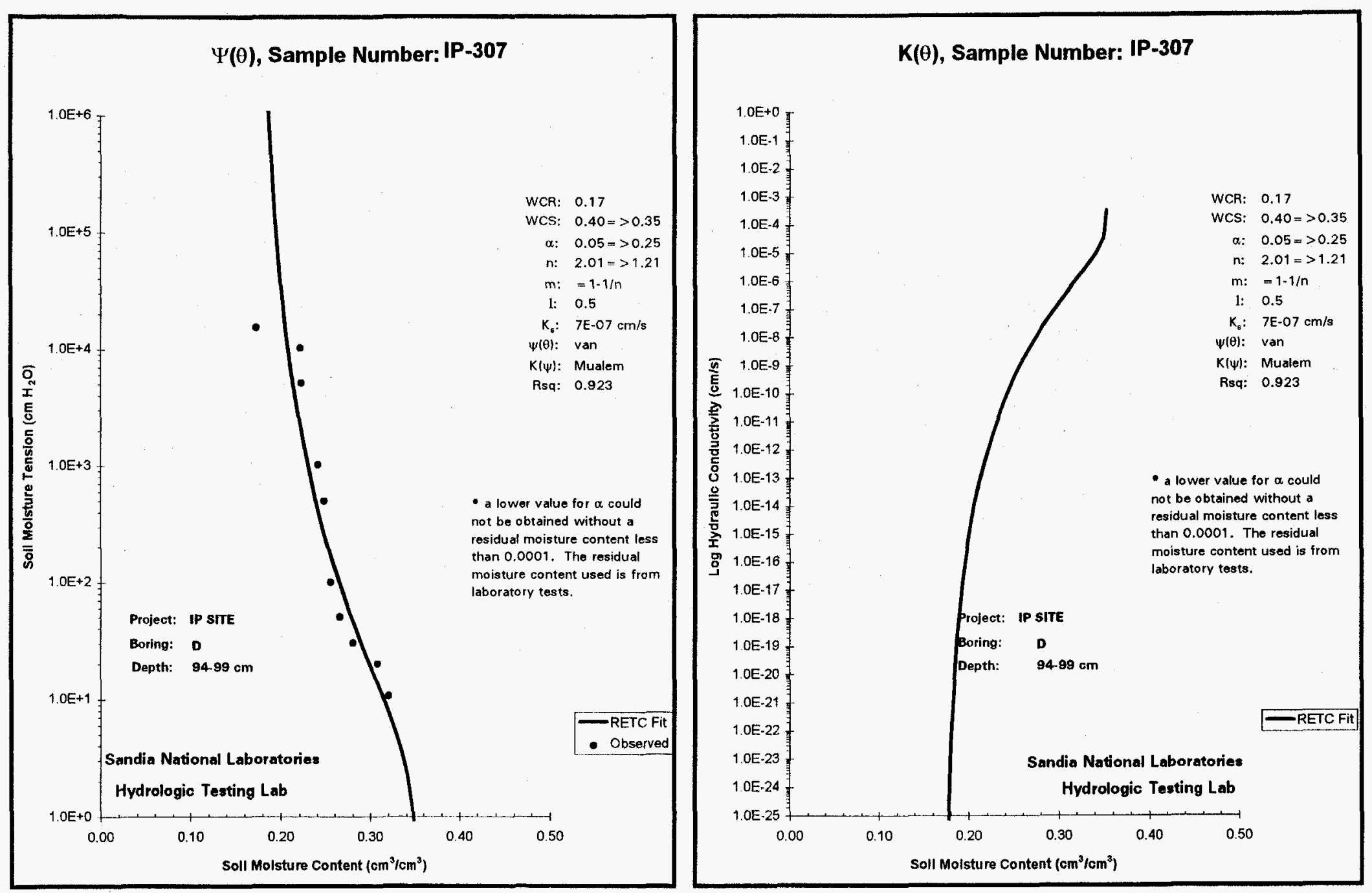

Figure A-8. RETC simulations of $\psi(\theta)$ and $\mathrm{K}(\theta)$ relationships for the laboratory-tested sample from $94-97 \mathrm{~cm}$ bgs. 

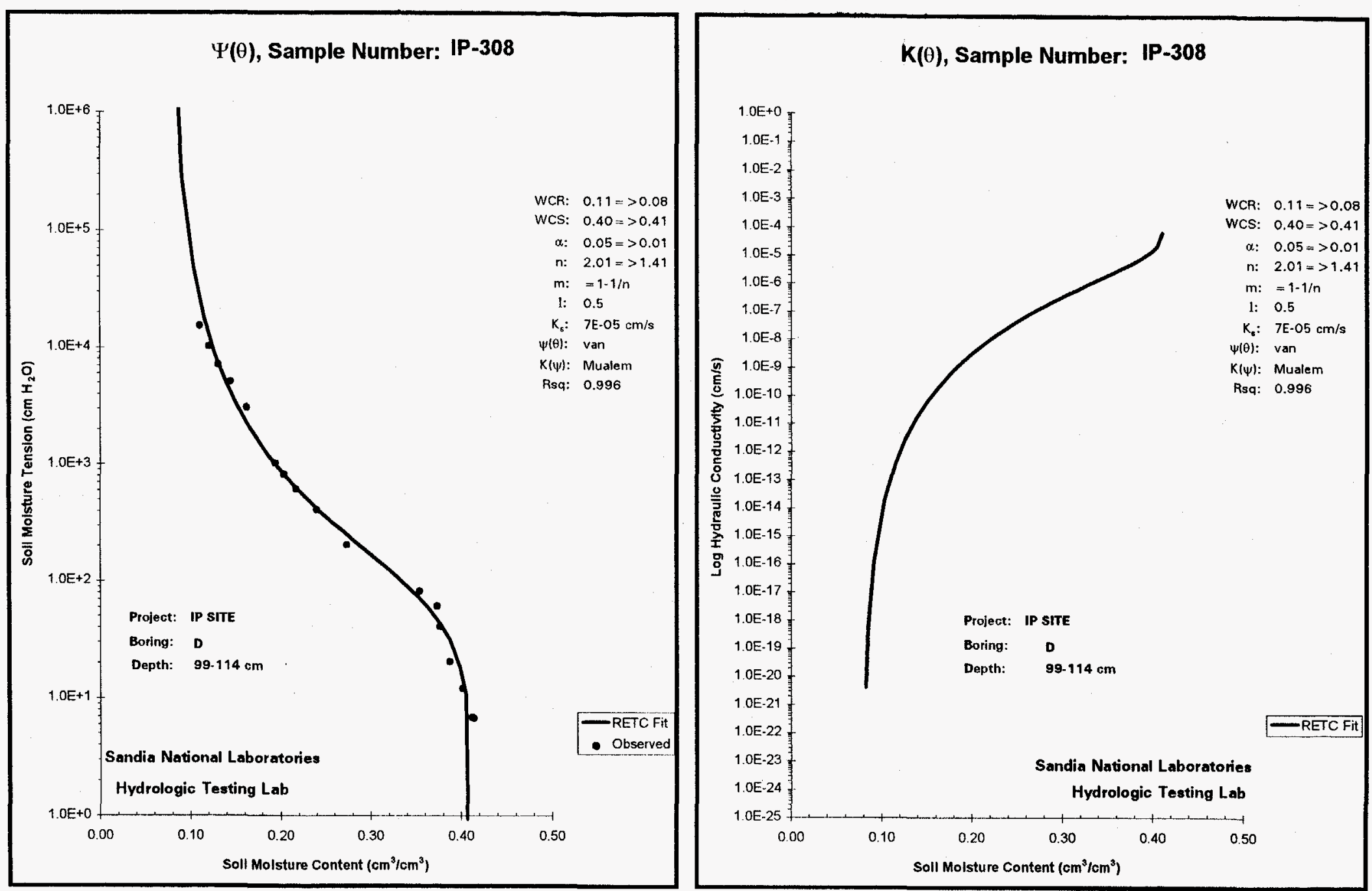

Figure A-9. RETC simulations of $\psi(\theta)$ and $\mathbf{K}(\theta)$ relationships for the laboratory-tested sample from $99-114 \mathrm{~cm}$ bgs. 

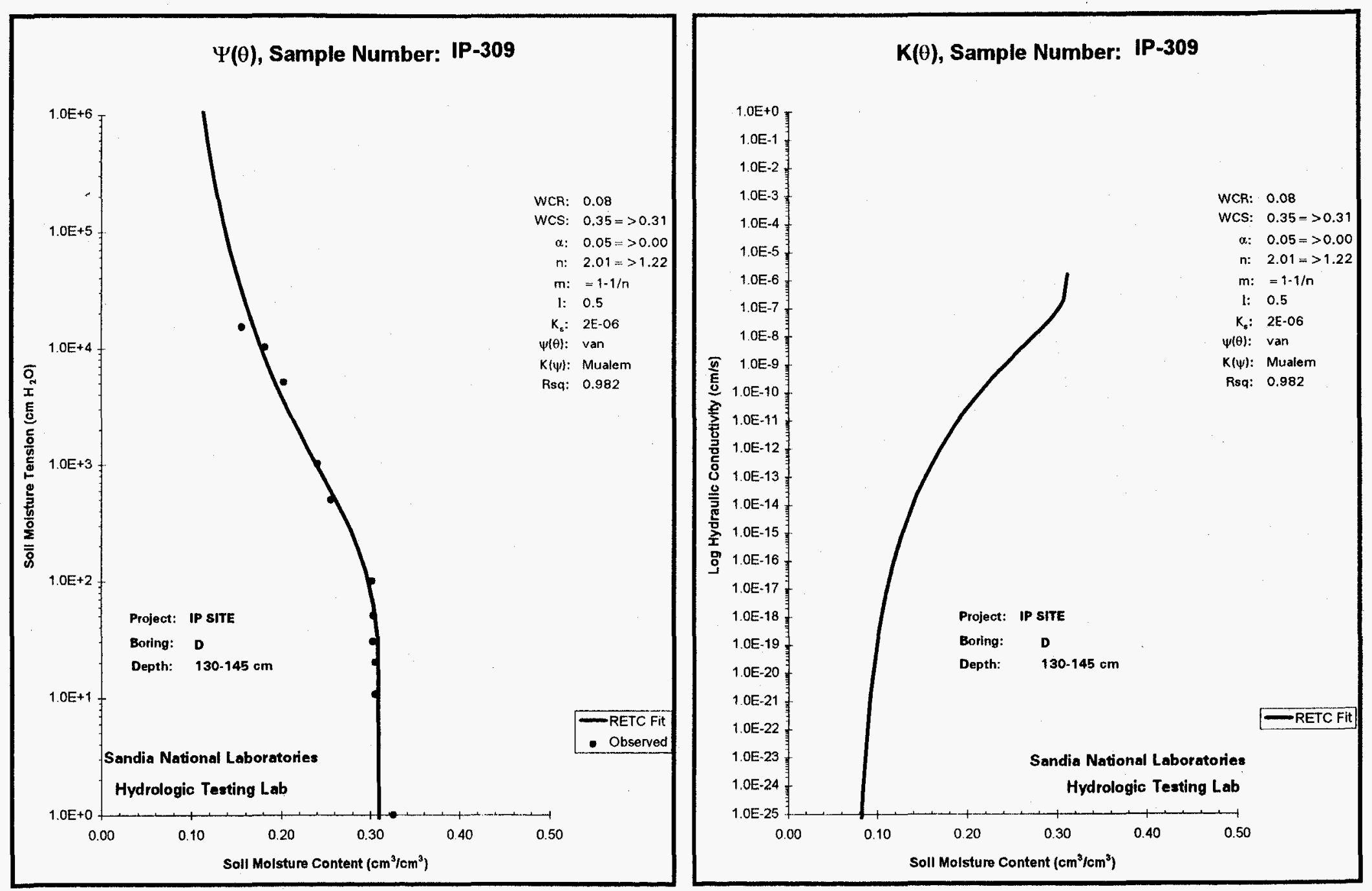

Figure A-10. RETC simulations of $\psi(\theta)$ and $K(\theta)$ relationships for the laboratory-tested sample from $130-145 \mathrm{~cm}$ bgs. 


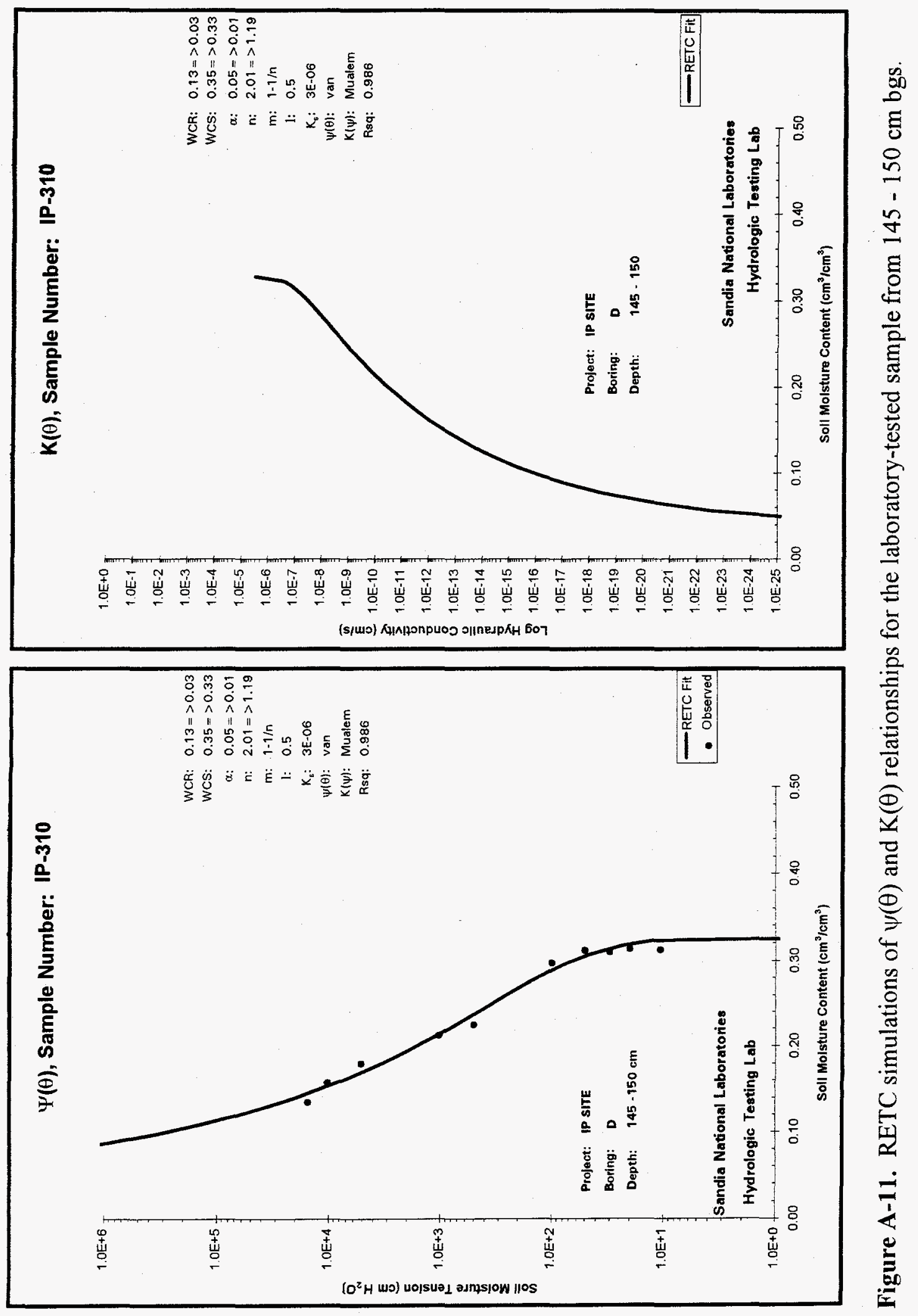




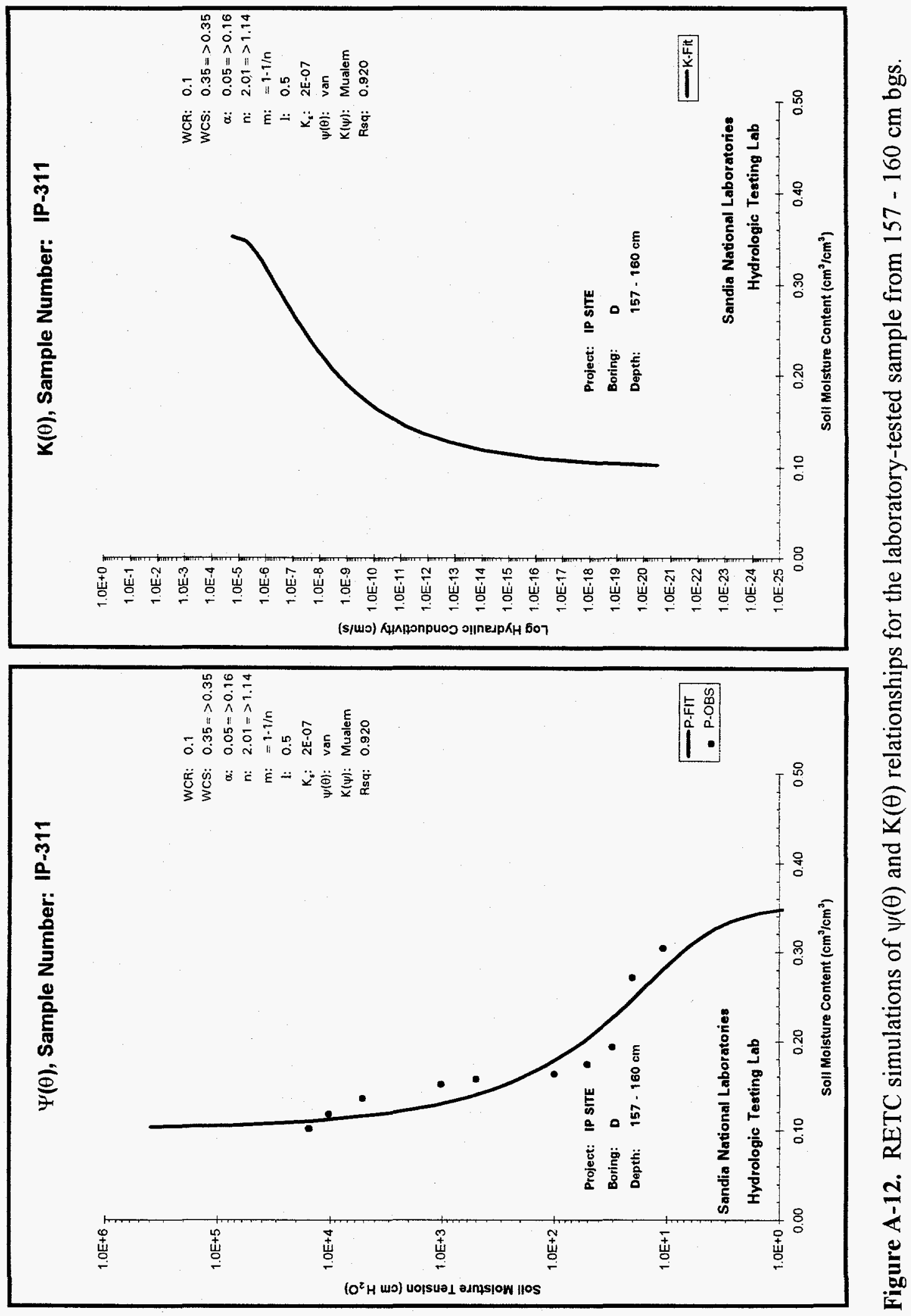



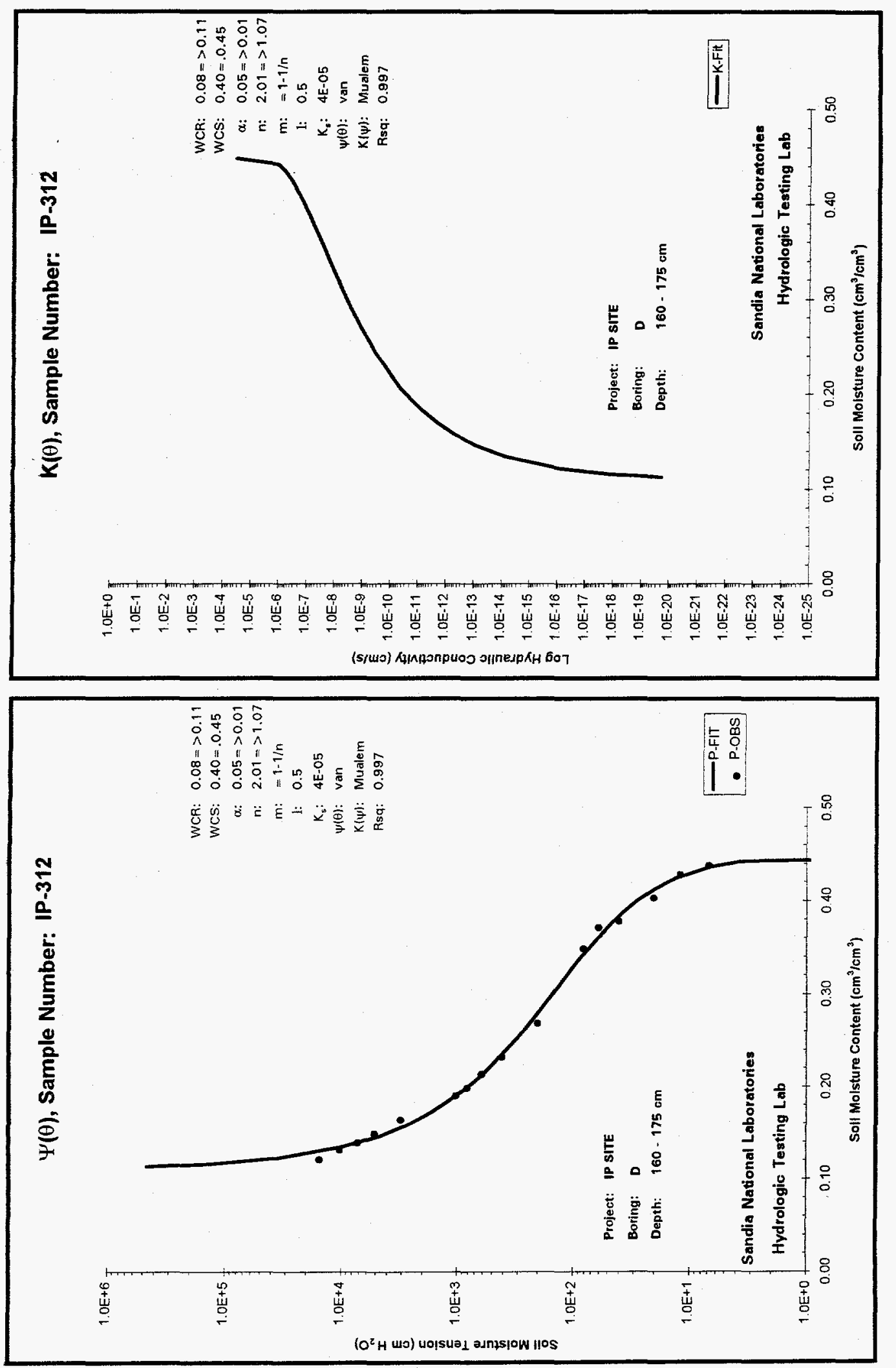

$\frac{n}{2}$ 


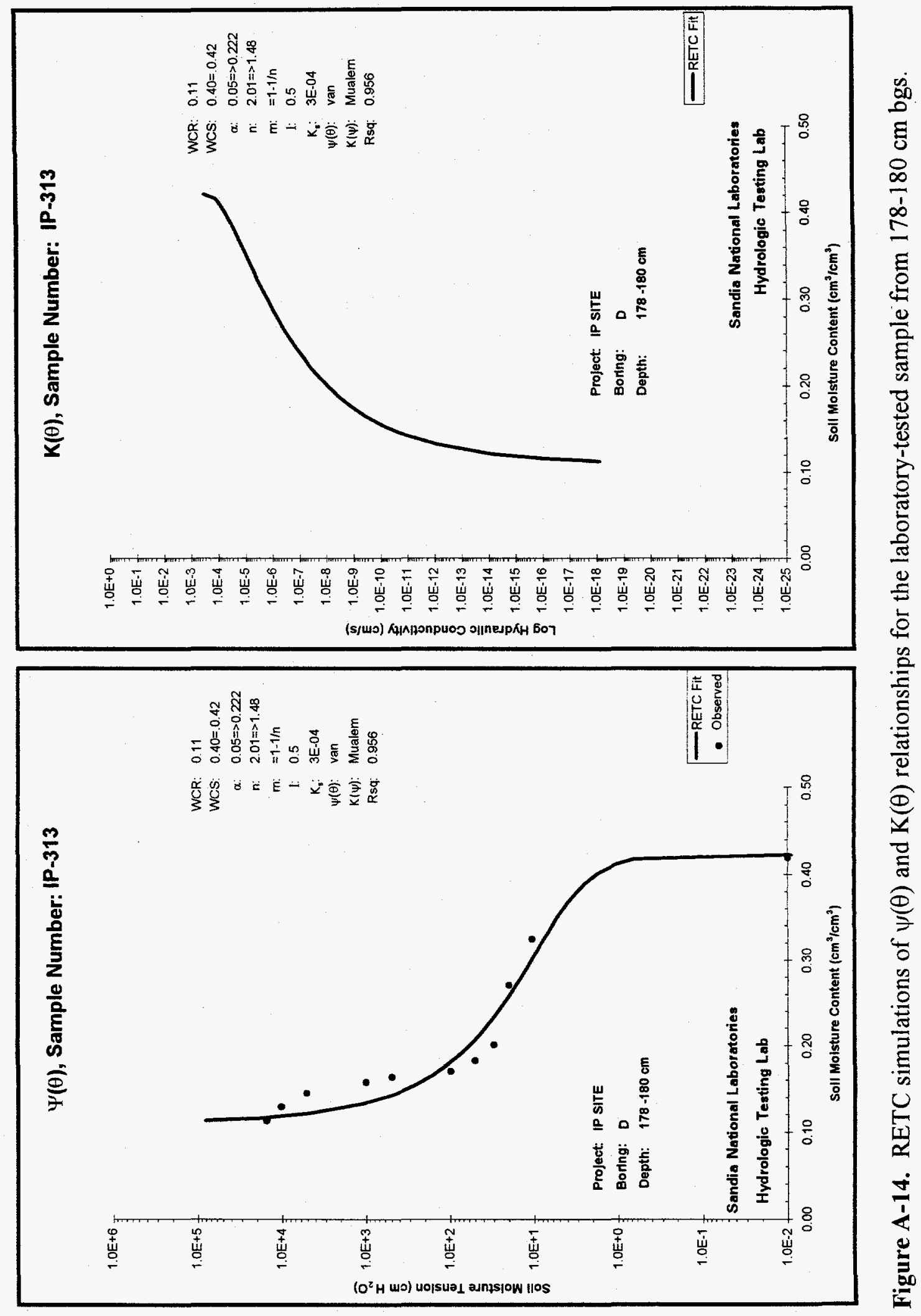




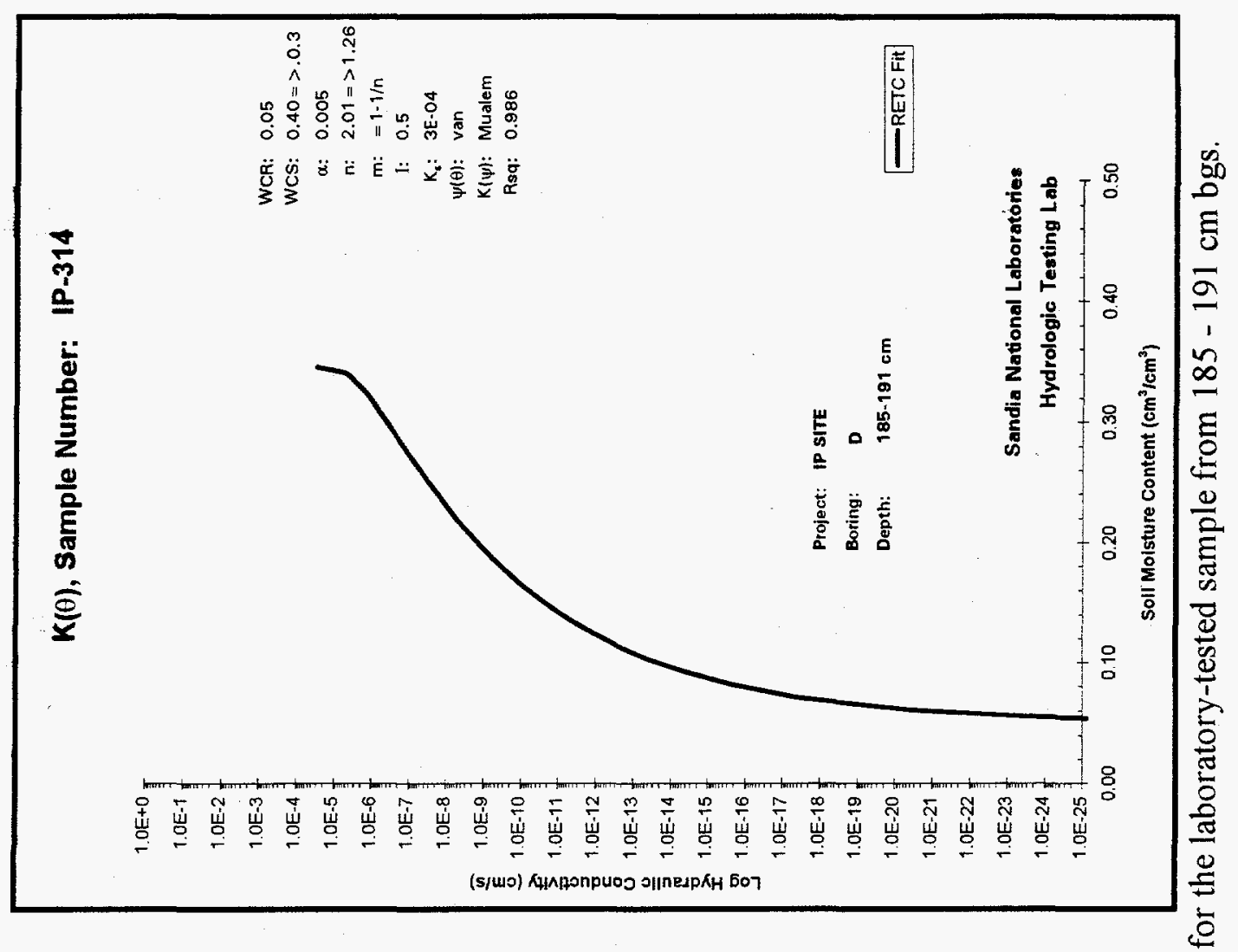

$\frac{1}{4}$

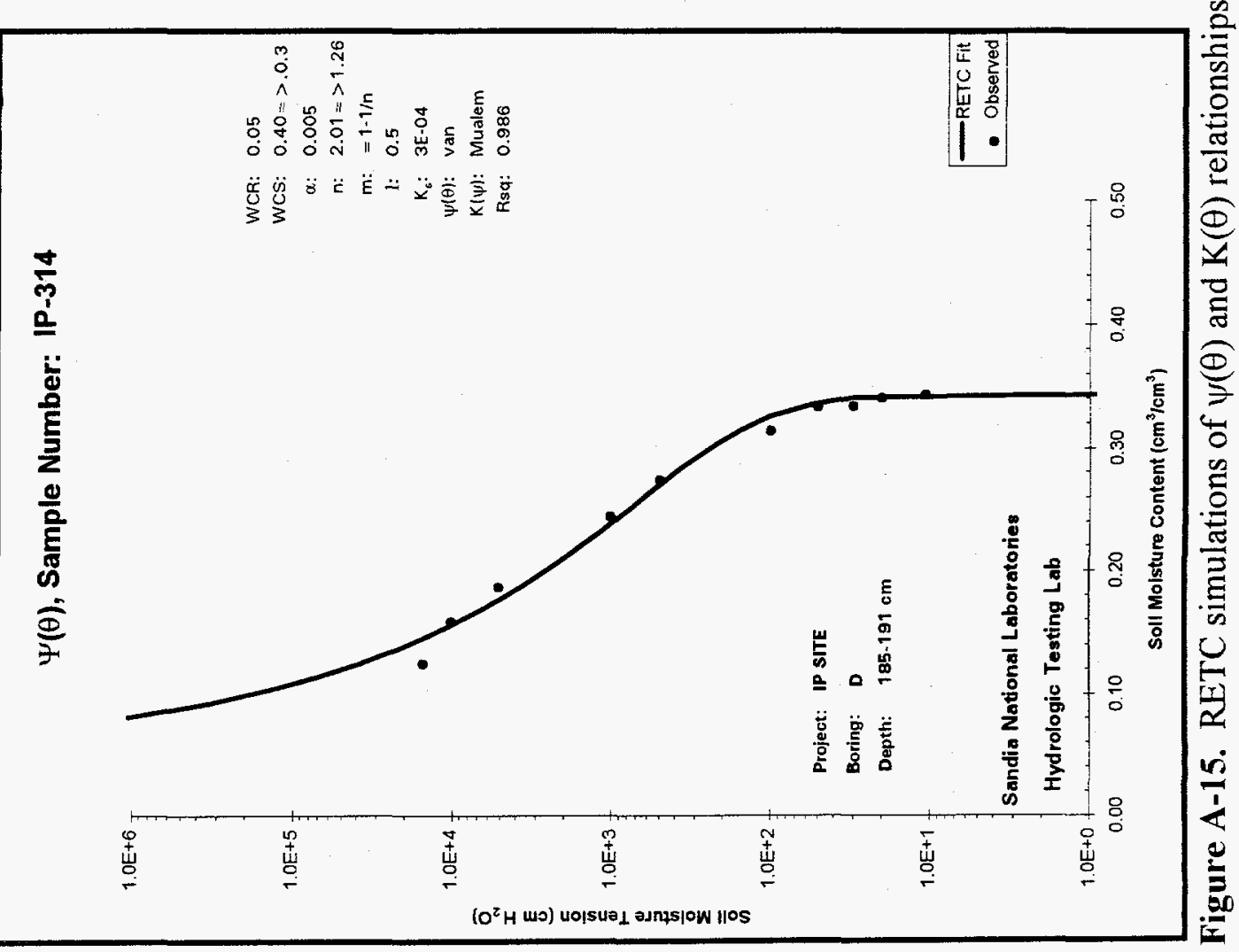



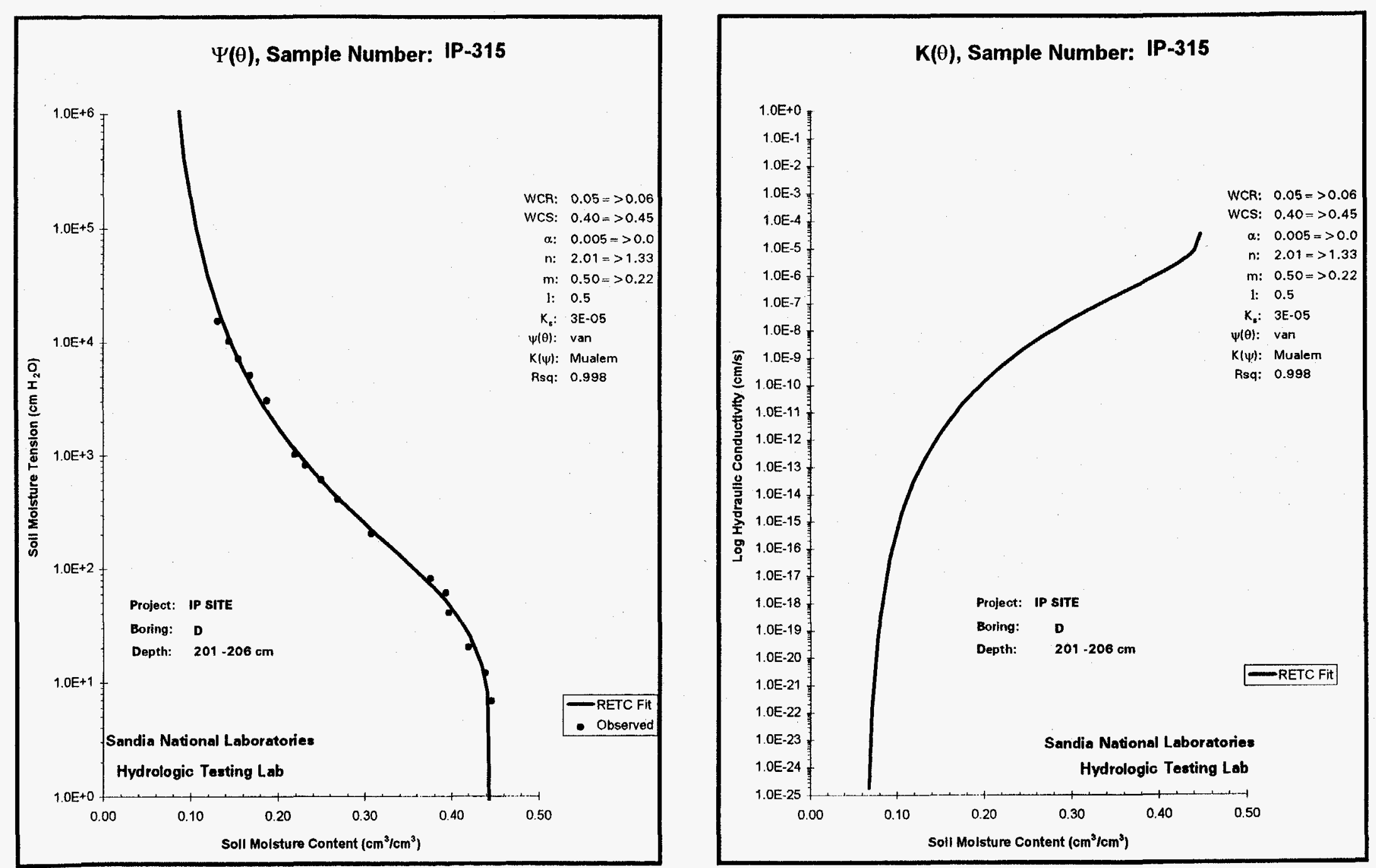

Figure A-16. RETC simulations of $\psi(\theta)$ and $K(\theta)$ relationships for the laboratory-tested sample from $201-206 \mathrm{~cm}$ bgs. 

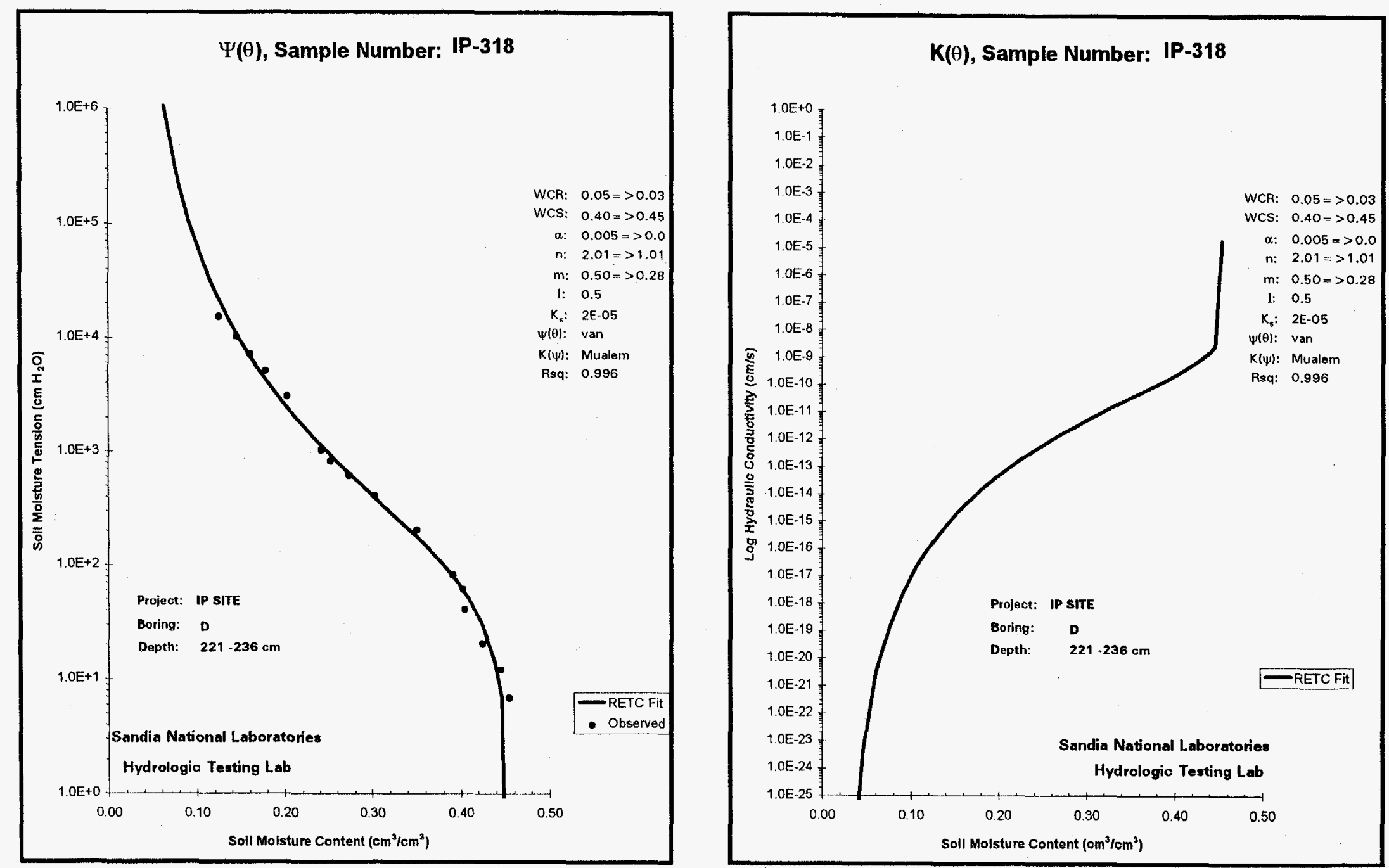

Figure A-17. RETC simulations of $\psi(\theta)$ and $\mathrm{K}(\theta)$ relationships for the laboratory-tested sample from $221-236 \mathrm{~cm}$ bgs. 


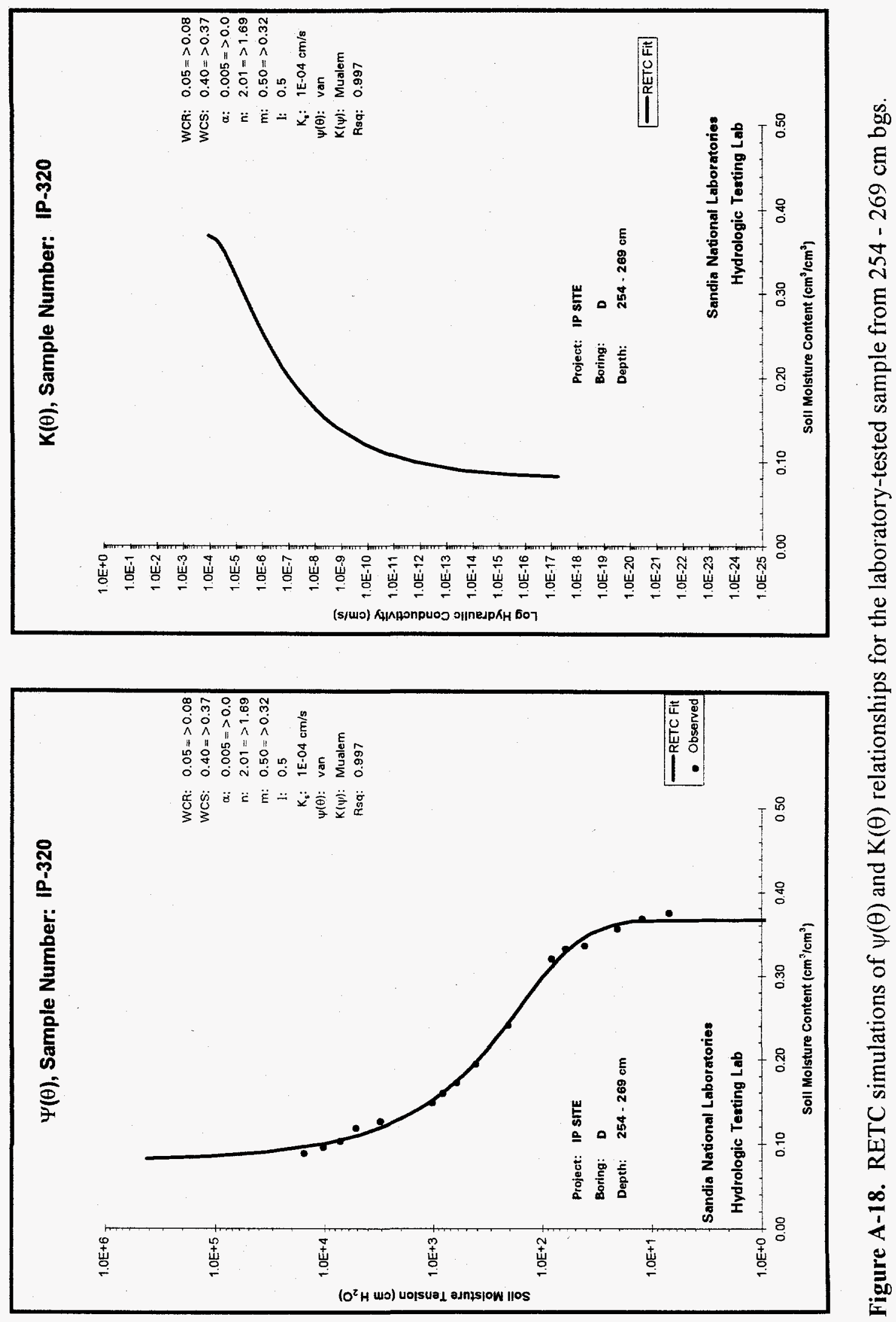




\section{Section 2.0 Graphs of RETC predictions of unsaturated hydraulic conductivity based on data from field infiltration results}

Section 2.0 present the results of RETC modeling of the $K(\theta)$ relationship based solely on data obtained during and after the infiltration event of the IP test. Results are presented beginning at the 15 to $45 \mathrm{~cm}$ interval bgs and ending with the 165 to $195 \mathrm{~cm}$ bgs interval. 


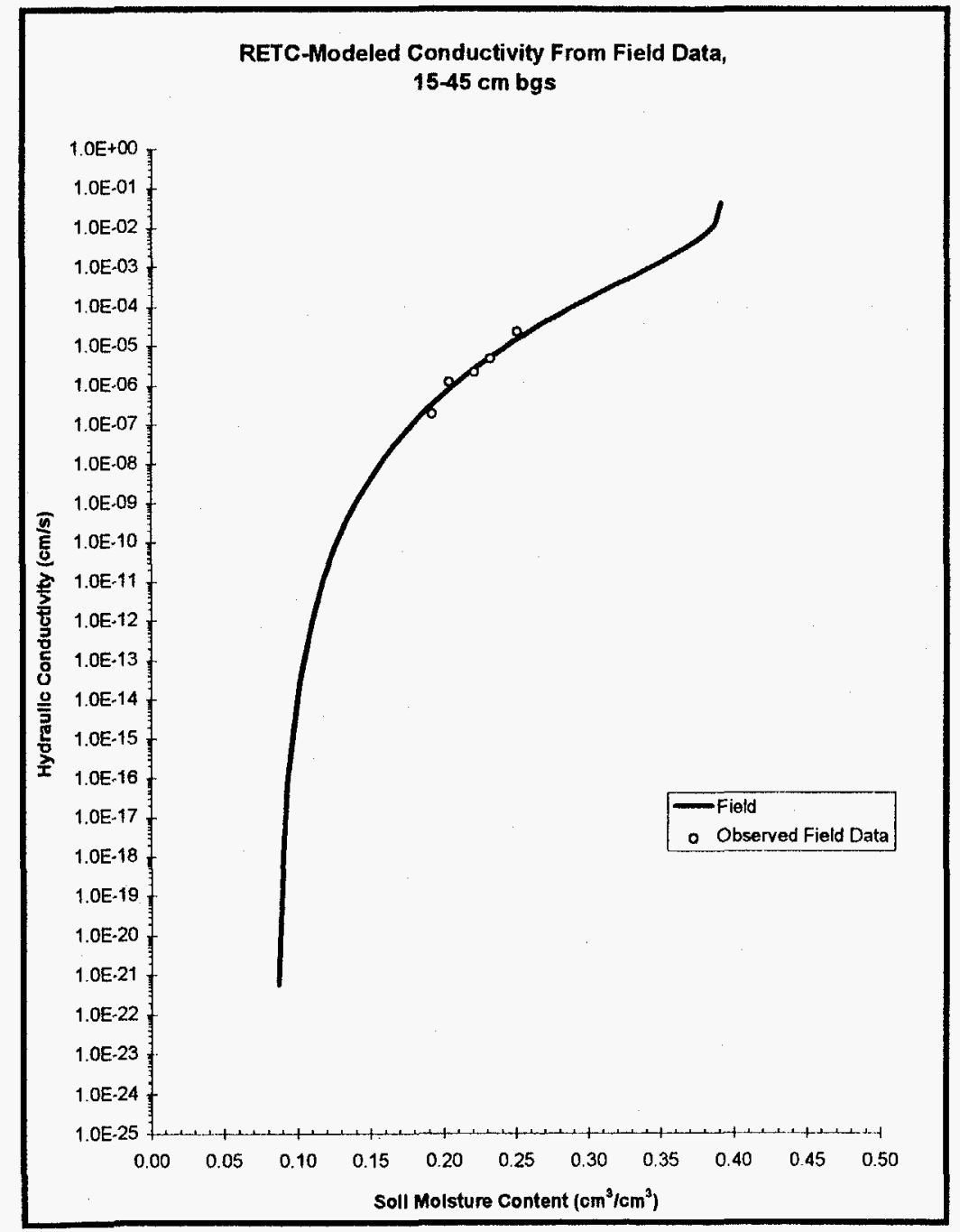

Figure A2-1. RETC prediction of $\mathrm{K}(\theta)$ from IP data at $15-45 \mathrm{~cm}$ bgs.

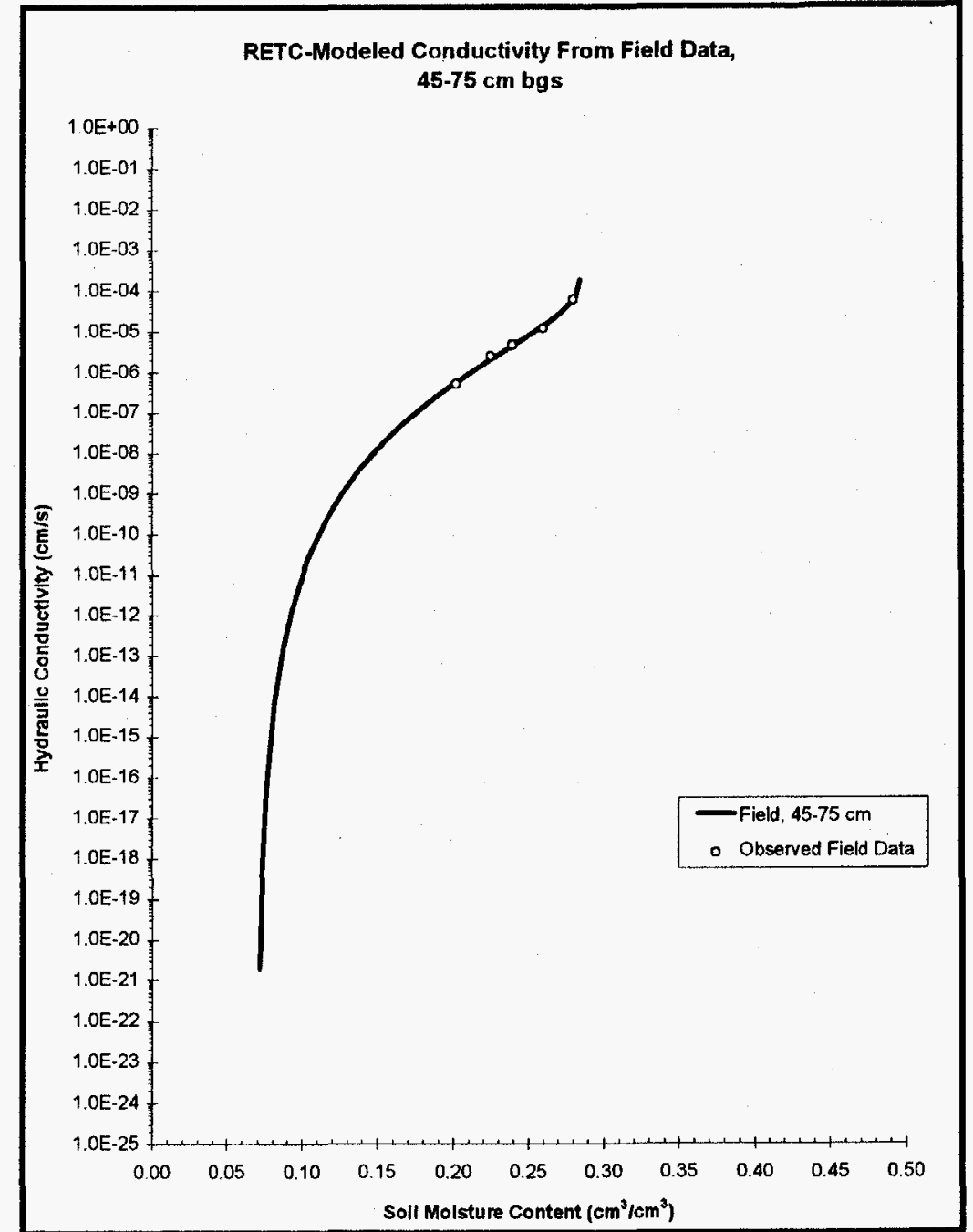

Figure A2-2. RETC predictions of $K(\theta)$ from IP data at $45-75 \mathrm{~cm}$ bgs 


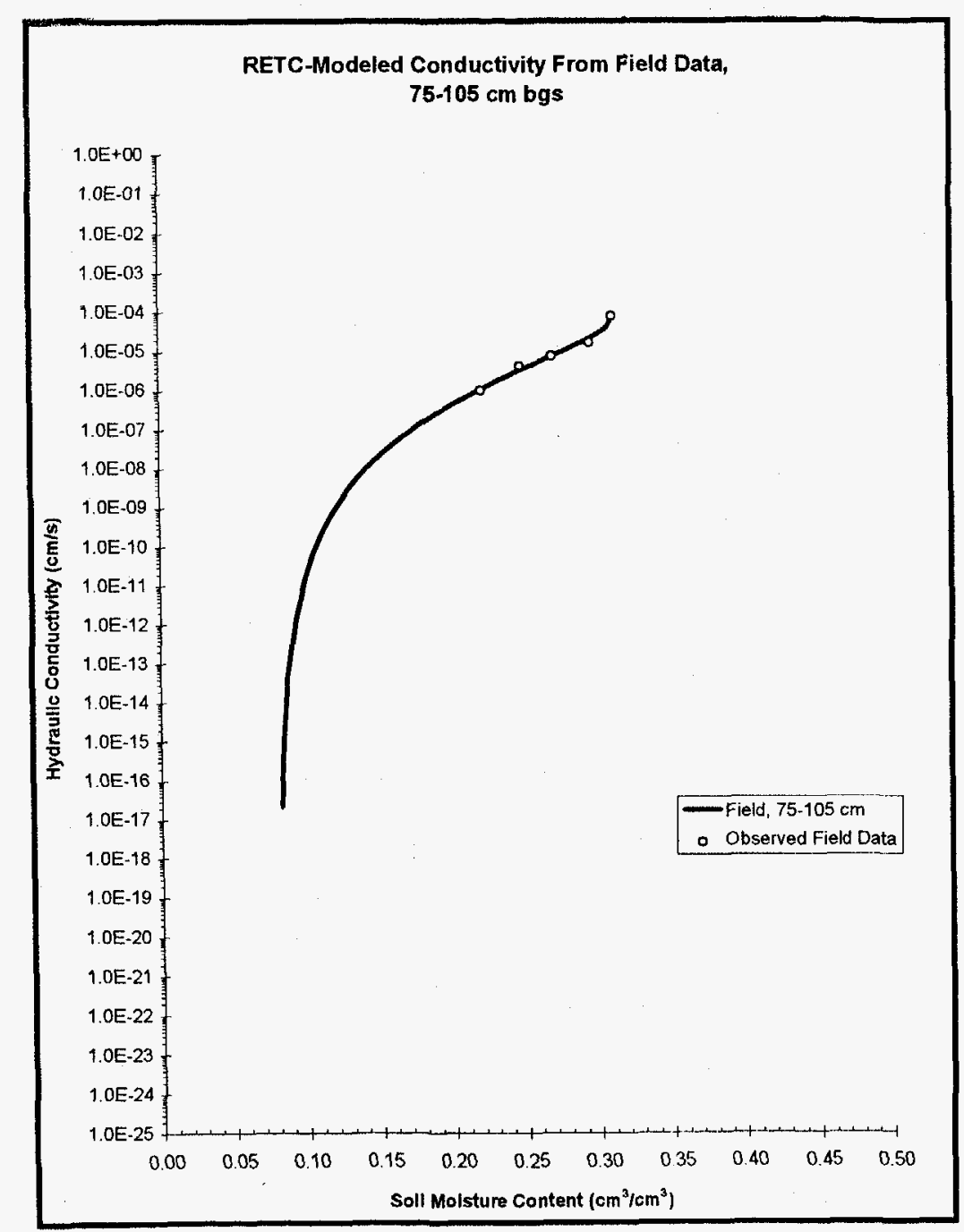

Figure A2-3. RETC prediction of $K(\theta)$ from IP data at $75-105 \mathrm{~cm}$ bgs.

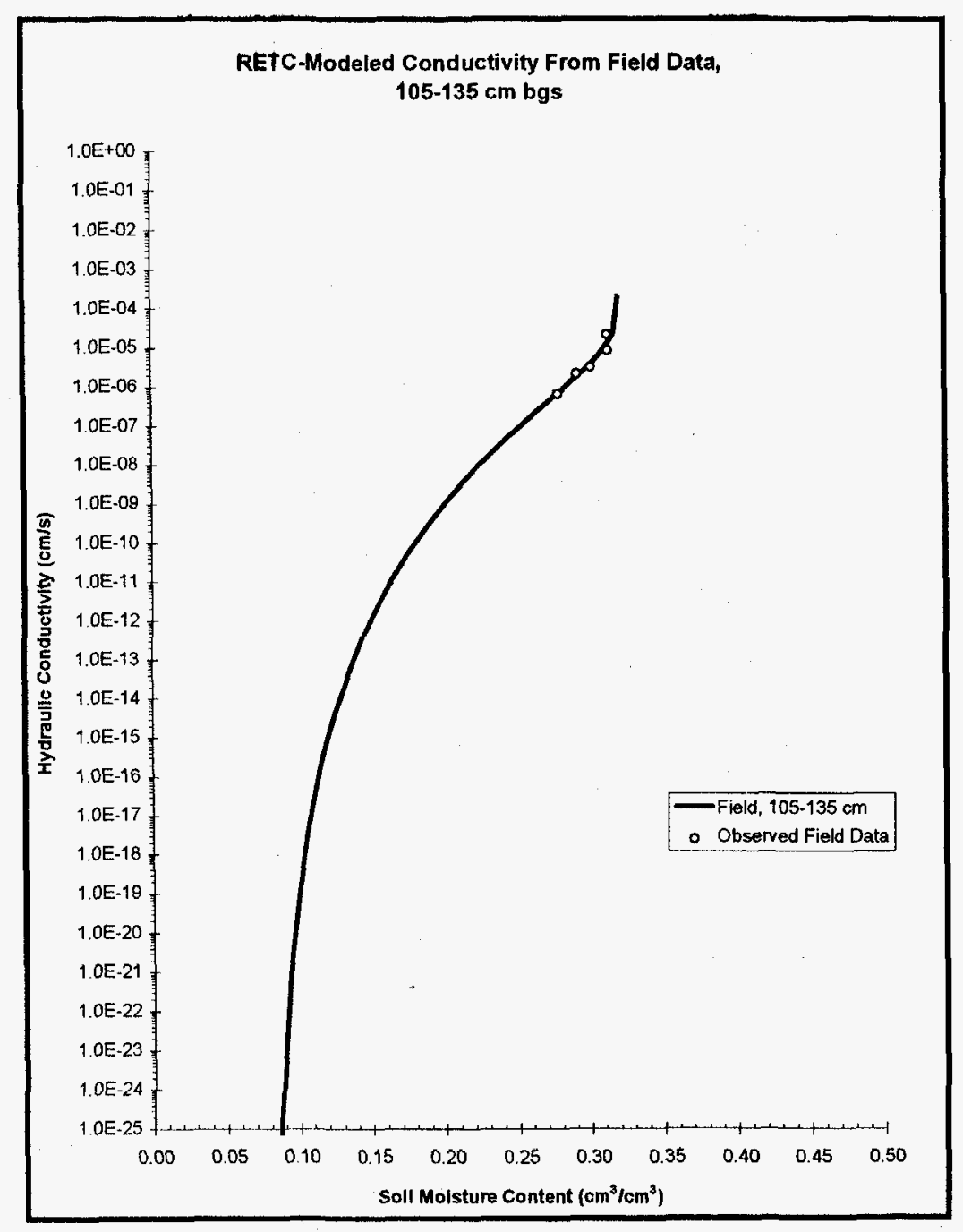

Figure A2-4. RETC prediction of $K(\theta)$ from IP data at $105-135 \mathrm{~cm}$ bgs 


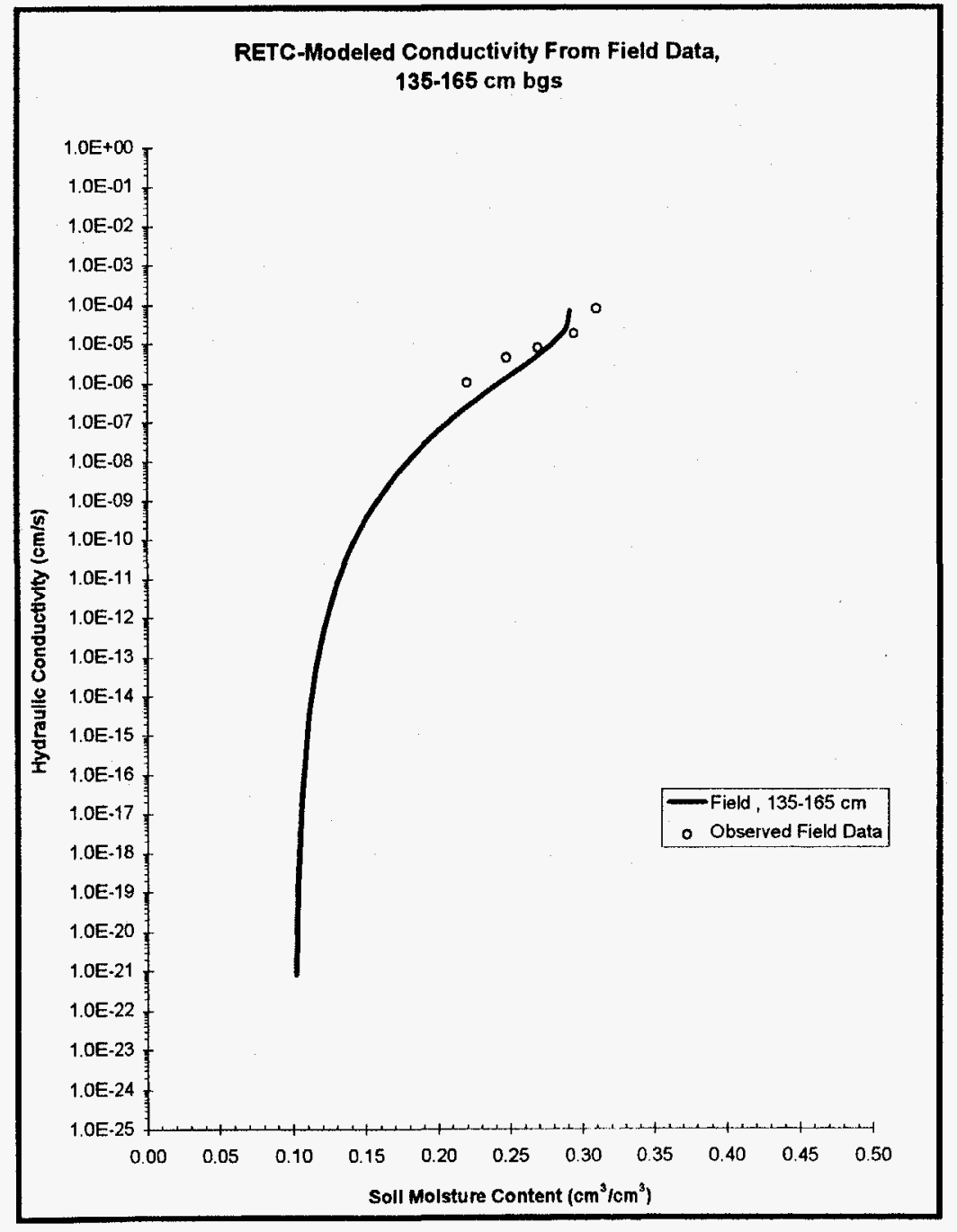

Figure A2-5. RETC prediction of $\mathrm{K}(\theta)$ from IP data at $135-165 \mathrm{~cm}$ bgs.

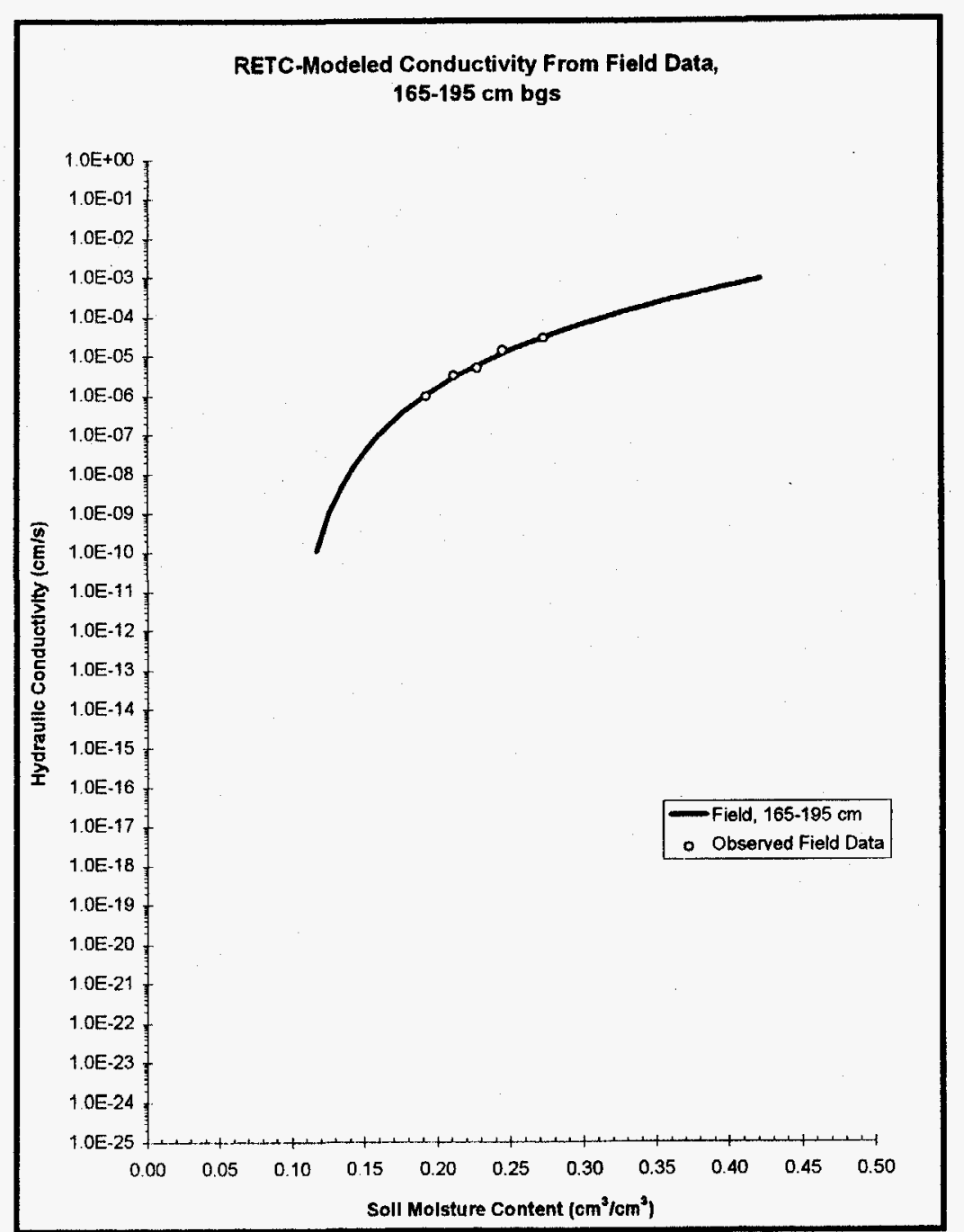

Figure A2-6. RETC prediction of $\mathrm{K}(\theta)$ from field (IP) data at $165-195 \mathrm{~cm}$ bgs. 


\section{Section 3.0 Graphs of RETC predictions of unsaturated hydraulic conductivity from data sets combining both lab and IP data}

Section 3.0 contains graphs of RETC predictions of the unsaturated hydraulic conductivity based on laboratory-tested $\psi(\theta)$ data combined with $\mathrm{K}(\theta)$ data from the IP test. Results are presented for $30 \mathrm{~cm}$ intervals beginning at $15 \mathrm{~cm}$ bgs and ending at $195 \mathrm{~cm}$ bgs.

For comparative and illustrative purposes, the $K(\theta)$ relationships for lab and IP data sets alone are also shown. 


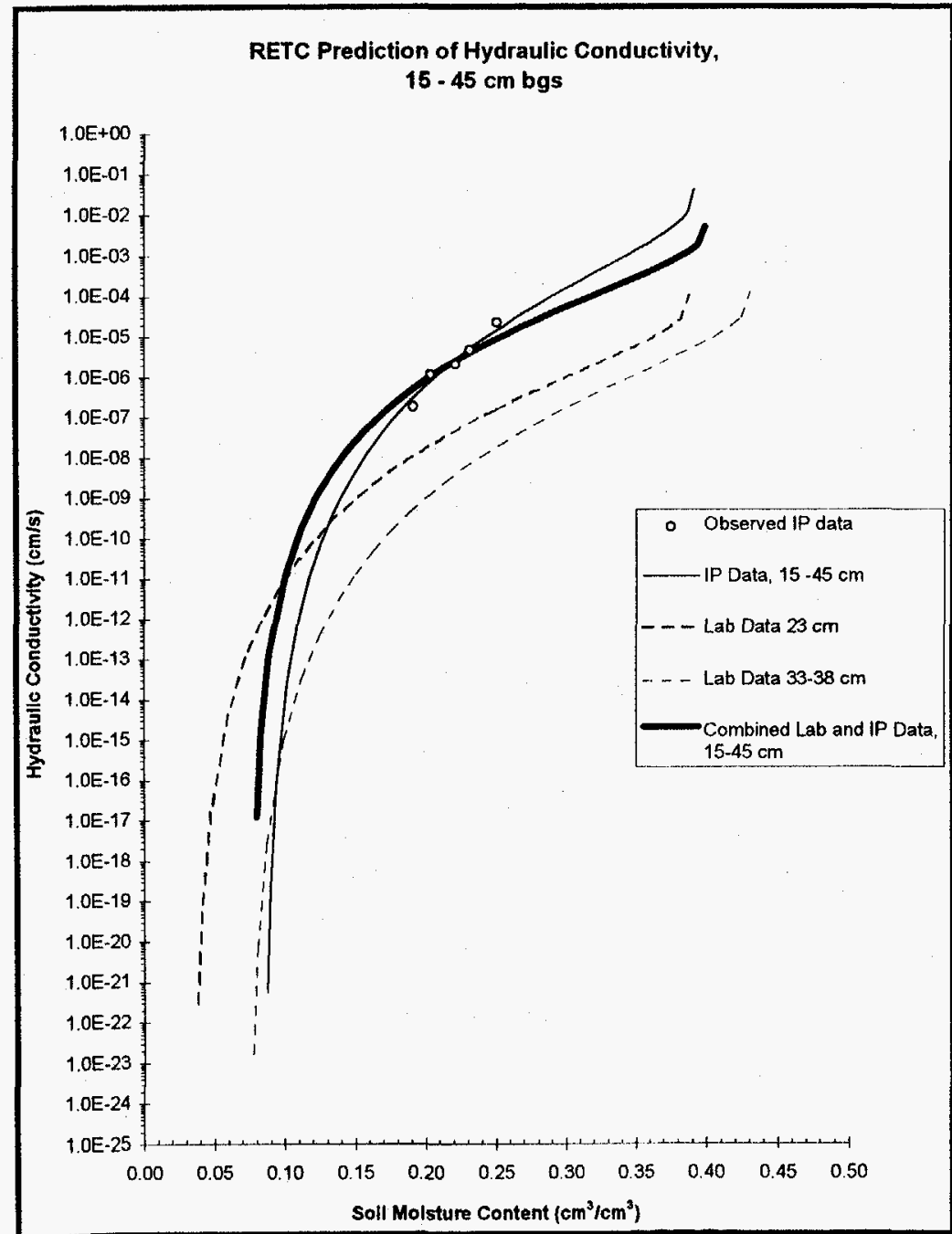

Figure A3-1. RETC-predicted $\mathrm{K}(\theta)$ relationships from IP, laboratory, and combined laboratory and IP data, $15-45 \mathrm{~cm}$ bgs.

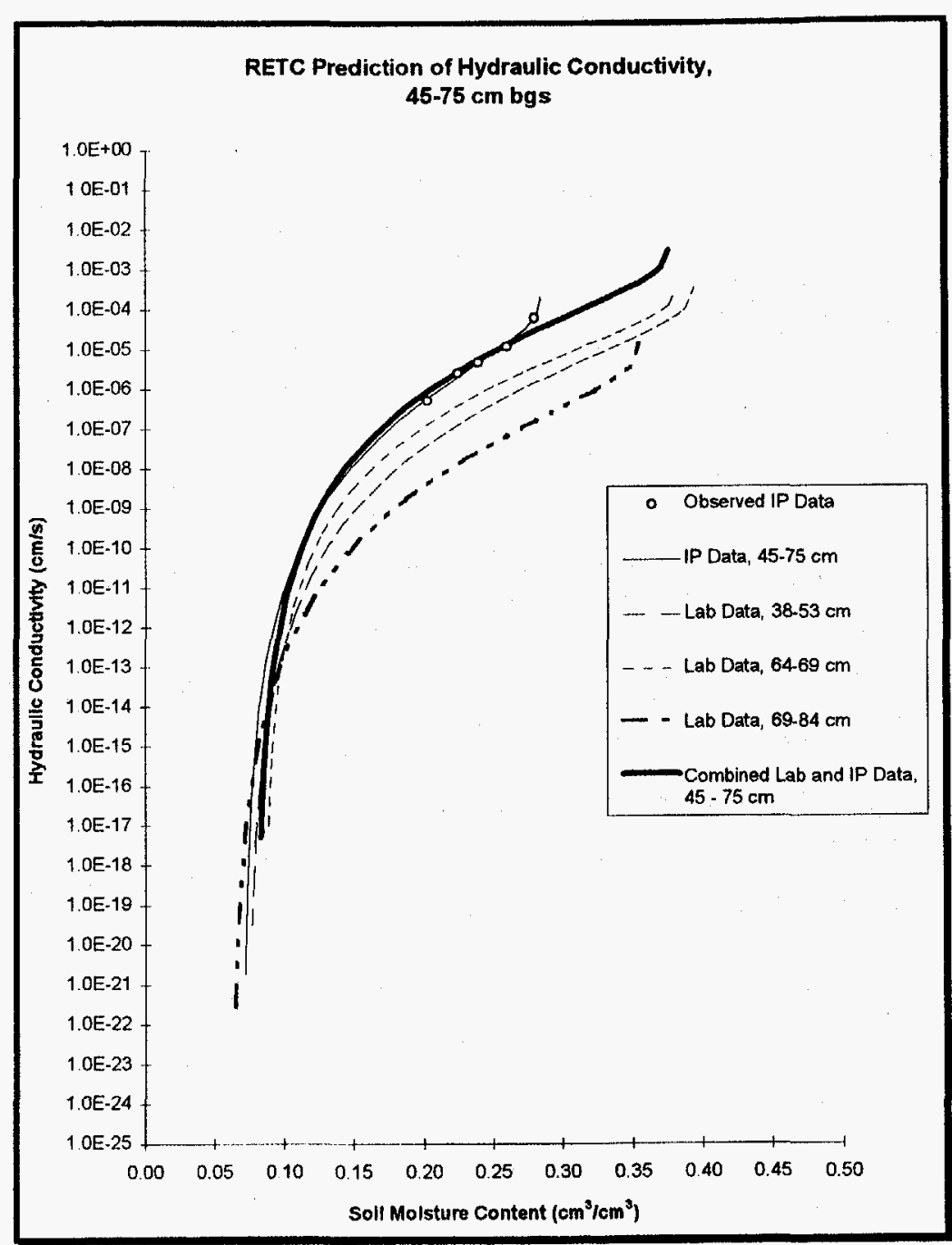

Figure A3-2. RE'TC-predicted $\mathrm{K}(\theta)$ relationships from IP, laboratory, and combined laboratory and IP data, $45-75 \mathrm{~cm}$ bgs. 


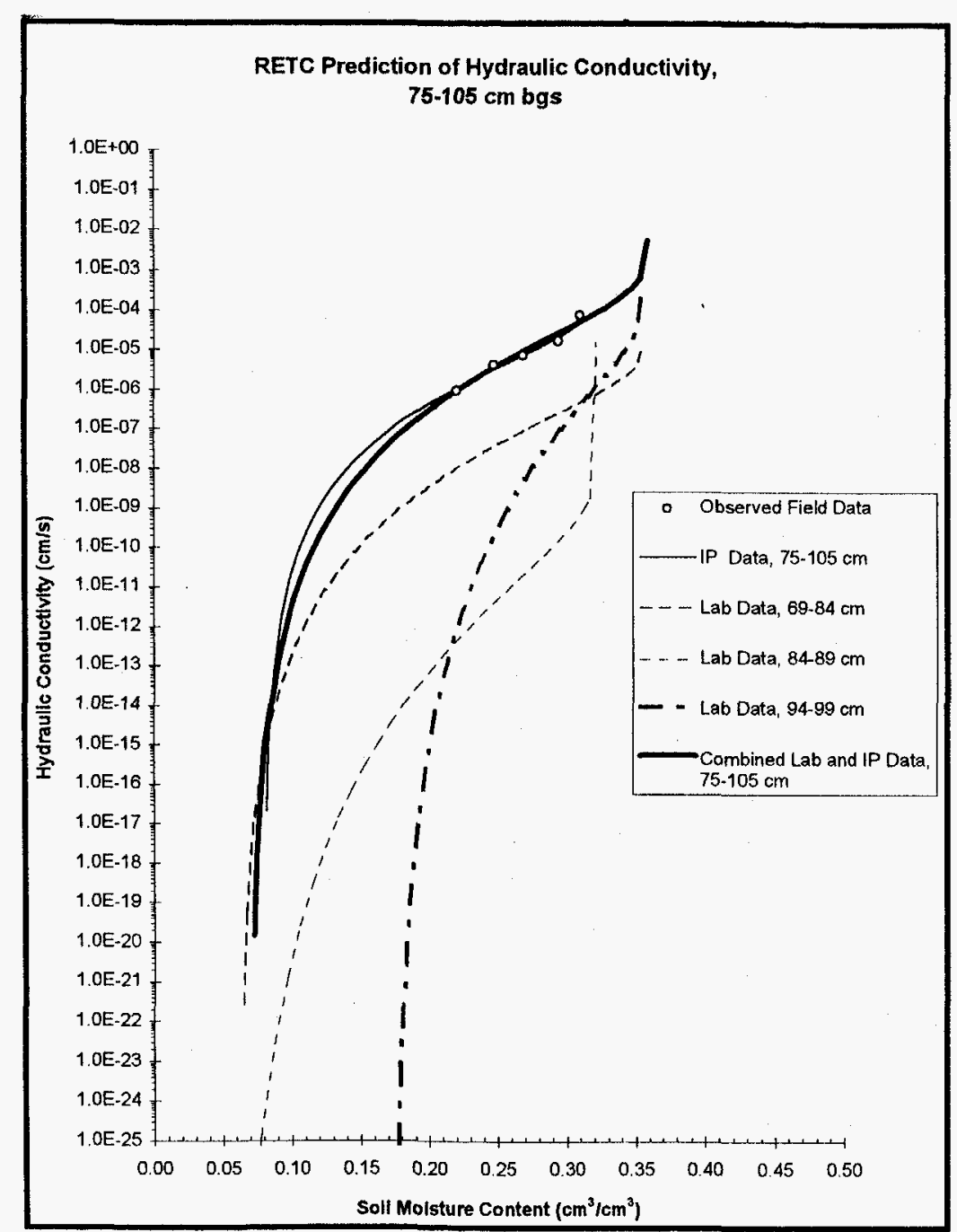

Figure A3-3. RETC-predicted $\mathrm{K}(\theta)$ relationships from IP, laboratory, and combined laboratory and IP data, $75-105 \mathrm{~cm}$ bgs.

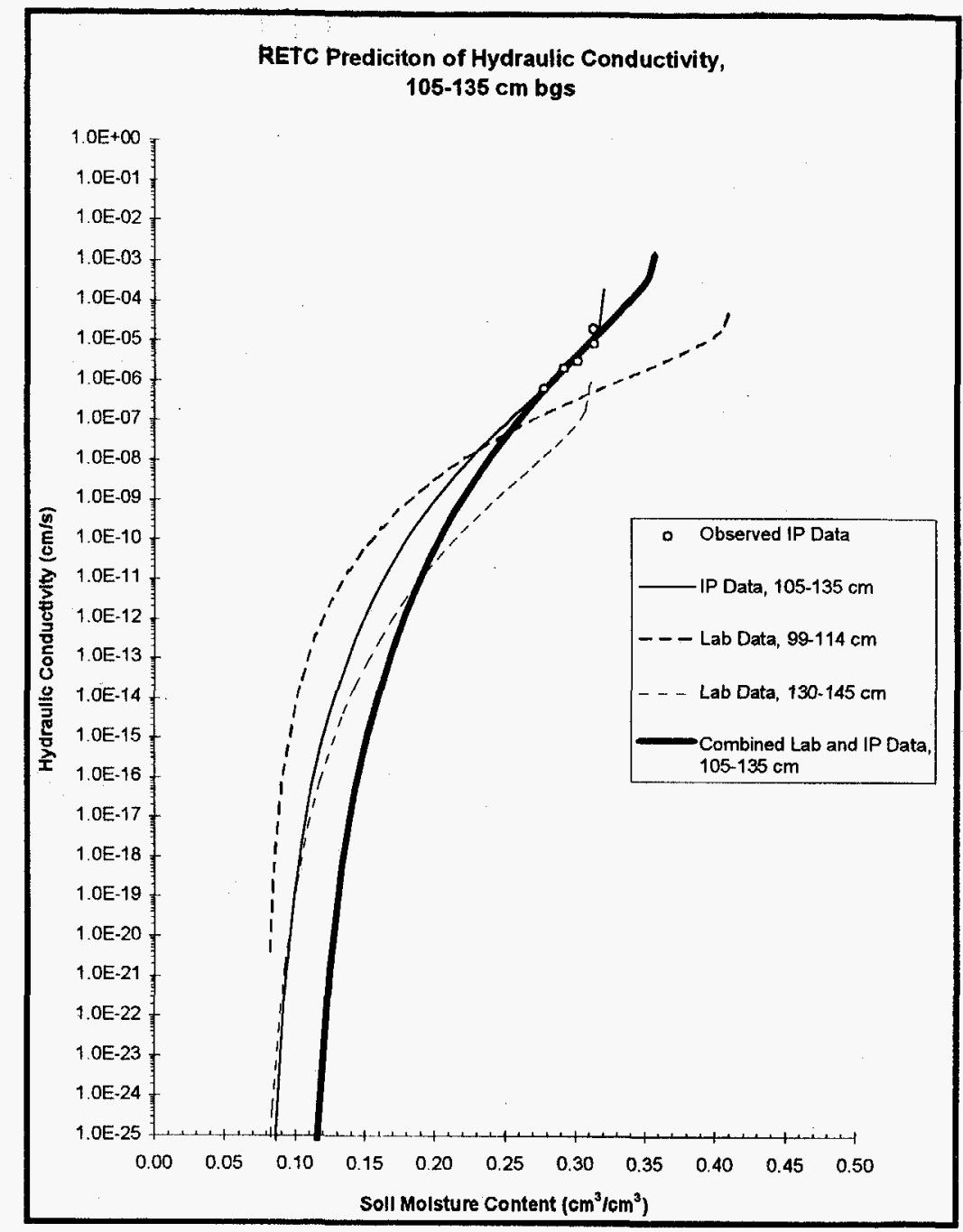

Figure A3-4. RETC-predicted $\mathrm{K}(\theta)$ relationships from IP, laboratory, and combined laboratory and IP data, $105-135 \mathrm{~cm}$ bgs. 


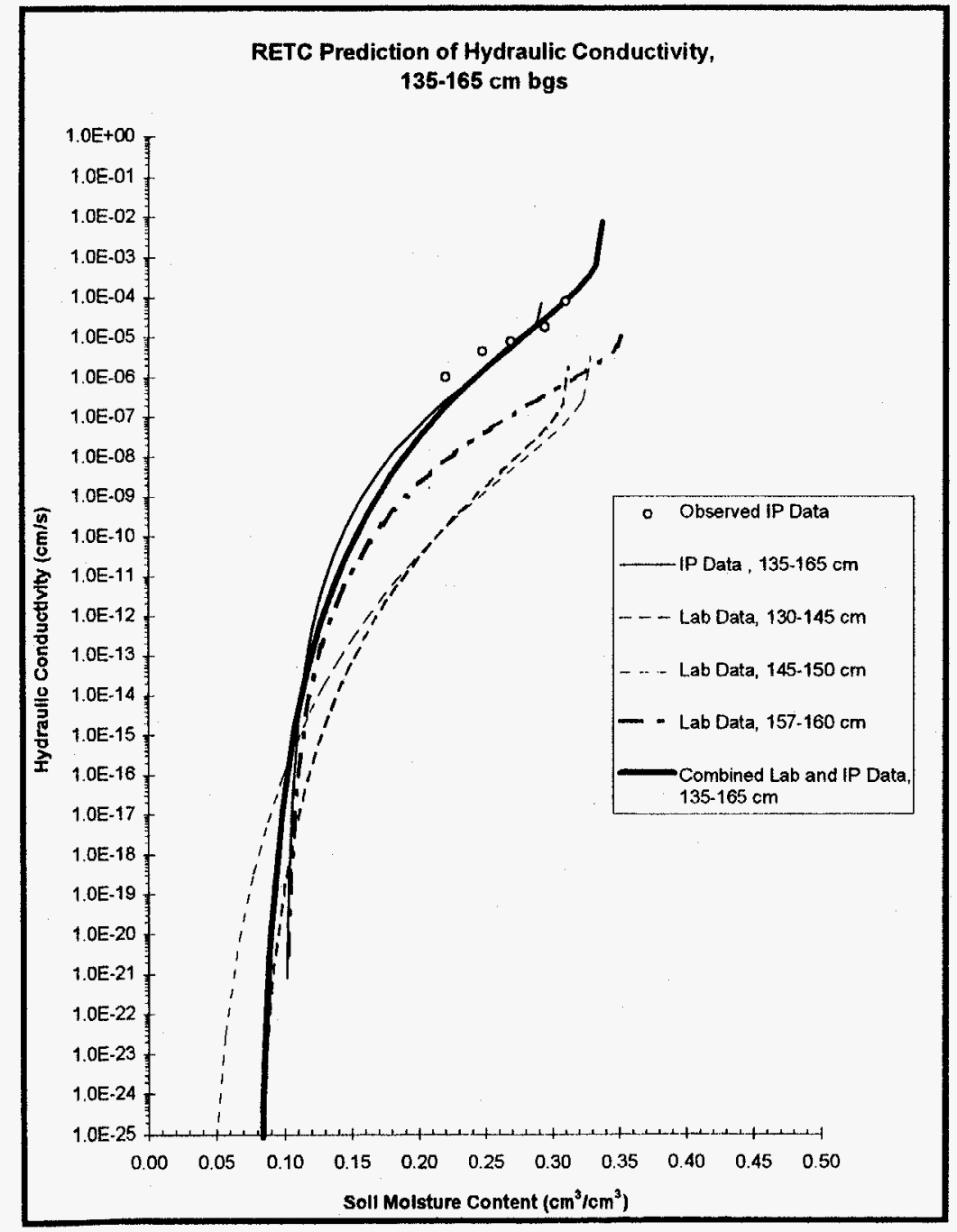

Figure A3-5. RETC-predicted $\mathrm{K}(\theta)$ relationships from IP, laboratory, and combined laboratory and IP data, 135 - $165 \mathrm{~cm}$ bgs.

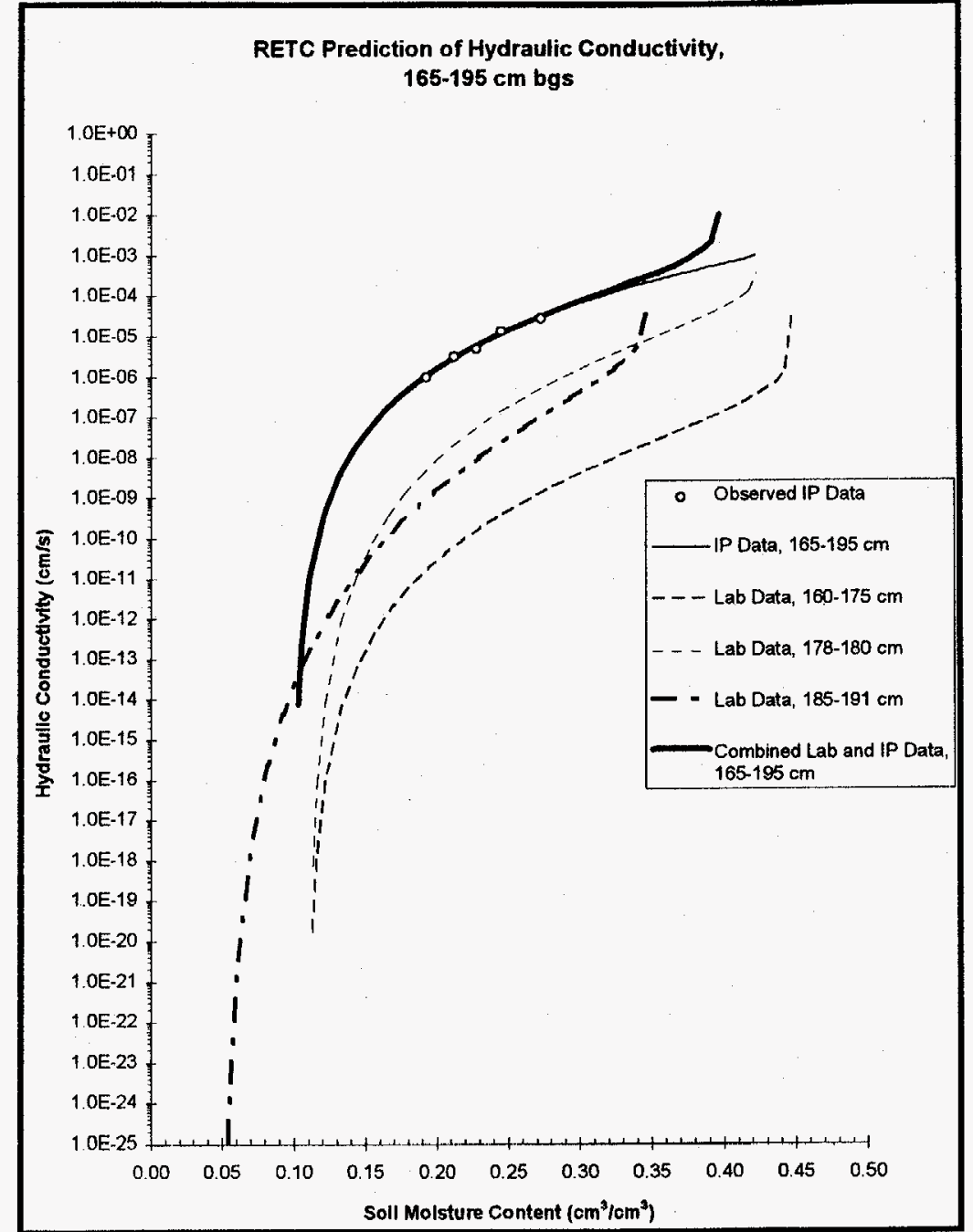

Figure A3-6. RETC-predicted $\mathrm{K}(\theta)$ relationships from IP, laboratory, and combined laboratory and IP data, $165-195 \mathrm{~cm}$ bgs 


\section{Distribution:}

1 David Peterson

INTERA, Inc.

1650 University Blvd.

Albuquerque, NM 87102

1 MS 0720 R.G. Knowlton, 6603

$1 \quad 1126$ H.A. Nyugen, 7584

11126 C.S. Roepke, 7584

11126 W.R. Strong, 7584

11148 R.E. Fate, 7585

11148 T.J. Goering, 7585

11148 E.A. Klavetter, 7585

11148 M.D. McVey, 7585

11148 J.L. Peace, 7585

$4 \quad 0184 \quad$ J.O. Johnsen, DOE/KAO

11309 Environmental Operations Records Center, 7512

19018 Central Technical Files, 8523-2

50899 Technical Library, 4414

20619 Review \& Approval Desk, 12630

For DOE/OSTI 
